\title{
El proceso civil y su futuro
}

\section{José Luis Vázquez Sotelo}

\section{El cambio social y la exigencia de un nuevo proceso civil}

La gran transformación social que supo profetizar en el primer cuarto del siglo XX aquel gran observador de la vida y de la sociedad que fue el filósofo español Ortega y Gasset, en su famosa obra «La rebelión de las masas", hace décadas que se ha consumado. En menos de medio siglo la profecía se hizo realidad. Solo que la realidad está superando enormemente a las previsiones. A la rebelión de las masas ha seguido la «sociedad de masas" y el salto cuantitativo de la "masificación», un término que el gran pensador no llegó a utilizar y que hoy define el momento presente. El desarrollo económico en varias zonas del mundo ha hecho surgir junto a la sociedad de masas la "sociedad de consumo». Han hecho su aparición los consumidores de toda clase de bienes y los usuarios de múltiples servicios.

La actividad económica y social más importante es hoy masiva: las antiguas tiendas y mercados van siendo desplazadas por las "grandes superficies»; el turismo antes propio de elites ha sido reemplazado por viajes organizados y masivos; se acude a las salas de cine y espectáculos guardando enormes colas y los jóvenes se divierten en grandes centros donde se amontonan formando grandes masas (como diría un clásico, «sicut pécora»); se han multiplicado los grupos sociales identificados como «usuarios" de toda clase de servicios y "consumidores» de toda clase de bienes.

De otra parte, han surgido increíbles adelantos técnicos que han revolucionado las condiciones de la vida de un modo que era inimaginable solo hace unas décadas. Hoy todos los ciudadanos van "comunicados" (aunque con frecuencia no tengan nada importante que comunicar) utili- 
zando diminutos aparatos con los que se puede hablar y recibir llamadas telefónicas de todo el mundo.

Las nuevas comunicaciones han permitido que sea cada vez más frecuente la contratación a distancia. Ha hecho su aparición la firma electrónica y la contratación electrónica. Al lado de las sedes y oficinas físicas de los bancos o compañías de financiación o de seguros han hecho su aparición la «sede virtual», el «banco virtual», etc.

El cambio social operado en la sociedad de nuestros días ha sido de mucha más envergadura que el producido en el siglo XIX cuando surgió la sociedad industrial y apareció el proletariado. ${ }^{1}$ La demanda de justicia social, ante el desafío de la globalización, es un reto que está sobre la mesa de los estadistas, de los gobernantes, de los economistas y de los juristas de todo el mundo.

En ese ambiente, que se va a reafirmar en el siglo XXI, el proceso civil se encuentra ante nuevos retos a los que ha de hacer frente. Se trata de intuir y en lo posible adivinar cuales serán las orientaciones del futuro proceso civil.

II. Primera premisa para el nuevo proceso civil: órganos adecuados, servidos por jueces profesionales, competentes y experimentados

Solo contando con jueces imparciales, independientes y responsables, pero también muy competentes y experimentados, puede asegurarse un proceso civil de calidad. Solo en manos de jueces bien seleccionados, mediante un método de ingreso y de promoción que asegure todas esas cualidades, es posible aceptar que las instituciones procesales de última generación puedan funcionar con la indispensable seguridad. Basta pensar en la ejecución provisional «ope legis», sin fianza, de las sentencias de primera instancia, o en la utilización imprudente de la coerción judicial, o en

1 Sobre el cambio social ya decía el civilista Diez-Picazo en su ensayo "Experiencias jurídicas y teoría del derecho" (publicado por primera vez en 1973): "Que este tiempo que nos ha tocado vivir es un tiempo de profundos cambios sociales, es algo que ninguno de nosotros dudará». "Es algo que está en el ambiente [...] delante de nuestros ojos", refiriéndose a que la «revolución tecnológica» está teniendo una influencia superior a la que tuvo la "revolución industrial", y ha conducido a un cambio radical en el repertorio de los comportamientos del hombre (p. 300 y ss.). 
la tutela anticipada, etc. Son todas instituciones que requieren ser manejadas por jueces prudentes y audaces a la vez. Poner esas creaciones en manos de jueces incompetentes, inexpertos o imprudentes, sería como poner en manos de soldados de reemplazo la utilización de las modernas armas con todo su poder de destrucción.

Todos conocemos a jueces a los cuales lo normal es que los tribunales superiores confirmen sus sentencias. La excepción es la revocación de dichas sentencias. Hay otros casos, sin embargo, a quienes la anulación de sus resoluciones es lo que frecuentemente sucede.

Proclamar la exigencia de buenos jueces para el futuro proceso civil es sin duda una obviedad. Pero bueno será recordar que la superioridad que se ha visto de la justicia inglesa frente a la europea continental — recordemos aquí a Calamandrei-, tiene como única explicación la selección muy cuidada de sus jueces. No solo no se conciben jueces prevaricadores ni jueces incompetentes o irresponsables, sino que la figura del juez está tan arraigada en la sociedad, que es respetada e incluso venerada después de su desaparición. En los mercados de antigüedades de Londres ( $v g$. en el popular mercado de Portobello) además de maletas y carteras de piel de cocodrilo utilizadas por antiguos Lores, se venden retratos de quienes fueron famosos jueces ingleses (no solo de Blasktone, Littleton, Coke, Mansfield o Eldon, sino también de otros más recientes), con los que se adornan las paredes de las casas particulares como nosotros podemos hacer con un gran artista, un gran literato o un gran científico. Me parece un ejemplo insuperable de una sociedad que estima y valora a «sus jueces", en los que confía que actuarán "sin favor y sin temor", que mediante resoluciones legales y justas sabrán defender la casa de cualquier ciudadano, por humilde que sea, como se defiende un castillo.

España, que ha sido siempre tierra de grandes juristas y que ha contado siempre con grandes jueces, en las dos últimas décadas no ha sido un ejemplo a imitar. Los métodos de selección pueden ser distintos, pero nunca se puede renunciar al control de calidad, como se ha hecho desde 1985 en que fueron «idoneizados» como jueces y magistrados profesionales a los que no se exigió (como sí se exige ahora) el necesario control de sus conocimientos jurídicos. En los últimos años las cosas han cambiando y puede decirse que se ha vuelto al cauce del que no se debió salir.

Conviene insistir y repetir que solo en manos de buenos jueces pueden dejarse las más avanzadas instituciones procesales. Ellos pueden asegurar que a esas creaciones no le sucederá aquello que decía Carnelutti respecto 
del derecho de acción procesal cuando la comparaba con un fusil que aunque suele disparar correctamente en ocasiones yerra en el disparo, con cierta frecuencia se encasquilla y otras veces suelta el tiro por la culata. $\mathrm{La}$ ejecución provisional de toda sentencia sin afianzamiento, la tutela de urgencia, la tutela anticipada, etc. son instrumentos de funcionamiento sumamente delicado, cuya utilización puede confiarse solamente a jueces expertos, experimentados y prudentes, ya que en otro caso estarían expuestas al fracaso y podrían producir daños incalculables.

\section{Segunda premisa: una justicia de rostro humano y un proceso civil que responda a las garantías fundamentales, permita llegar a resultados fiables y sea eficaz}

1. "Justicia de rostro humano", que fue el gran lema de un famoso Congreso internacional, significa proceso verbal y público, en una o varias audiencias, aunque sin renunciar a la escritura en los actos de alegaciones iniciales, que exigen reflexión y tiempo. Significa presencia inmediata del juez, concentración de los trámites, igualdad de derechos y oportunidades para todas las partes.

Proceso eficaz significa que la respuesta judicial llegue a tiempo y se convierta en hechos tangibles, no limitándose a meras declaraciones o pronunciamientos platónicos.

En punto a la oralidad la nueva Ley de enjuiciamiento civil española ha significado (tal como quedó después de casi mil enmiendas) un verdadero salto cualitativo. Debo precisar que más que a las disposiciones de la ley (que ya existían en la ley derogada, solo que eran "letra muerta") el cambio ha sido propiciado por la utilización de los medios de registro de la palabra, de la imagen y del sonido. El Secretario se limita a certificar que se celebró la sesión, que ha sido registrada en el correspondiente $d v d$, del que se entrega una copia a cada parte, y en el que, bajo pena de nulidad, tienen que aparecer el juez, el Secretario y los demás protagonistas y personas que intervienen en la sesión. Gracias a esa innovación, el proceso civil declarativo español ha pasado del "solemnis ordo iudiciarius" de la edad media al proceso verbal u oral de los modernos Códigos procesales, que debe ser el proceso civil del futuro. Ahora ya los litigantes ven la cara del Juez que va a juzgar su caso. Las sesiones orales, dirigidas por el juez, propician más conciliaciones y transacciones que antes. 
Es cierto que con la oralidad no basta. Es necesario dotar al Juez de todos los poderes necesarios para que pueda cumplir con eficacia su misión, entre ellos, singularmente, los poderes de coerción y los poderes e iniciativas sobre la prueba. En este aspecto, la nueva LEC española ha significado un increíble retroceso, una involución que deja nuestro proceso civil en situación peor en la que se encontraba a finales del siglo XIX, como después comentaré al referirnos a la prueba.

2. El futuro proceso civil no puede desarrollarse de espaldas a las innovaciones tecnológicas. La utilización de la informática, la telemática, los adelantos electrónicos, de las nuevas técnicas probatorias (entre cuyos ejemplos sobresalientes y de uso cotidiano pueden citarse los análisis de los marcadores genéticos y del ADN en los procesos sobre filiación, o las pruebas de balística o los análisis químicos) tienen que ser utilizadas en el proceso, aunque siempre dentro del contradictorio y con las debidas garantías para las partes.

Un proceso de rostro humano, con las necesarias garantías y una respuesta judicial en un plazo razonable, para que la justicia no llegue tarde a la representación, (según una conocida expresión de Calamandrei referida a la opera bufa por la impuntualidad de los asistentes), y en el que el juez disponga de los poderes necesarios para que el resultado del proceso sea eficaz, es el modelo al que debe responder el proceso del futuro civil.

Esta exigencia plantea problemas de organización judicial, de dotación de los órganos jurisdiccionales con los adecuados medios humanos y materiales. Más que un problema doctrinal supone una dificultad organizativa y de dotación presupuestaria.

\section{El juicio de primer grado como gran protagonista del proceso civil}

El proceso civil de primer grado o «juicio de primera instancia», tiene que ser el gran protagonista del proceso. Debo recordar en este punto la lección con la que Morello clausuró uno de los últimos congresos celebrados en Argentina, en la que defendió este punto de vista.

Después de una primera instancia rodeada de todas las garantías de acierto, deben venir los recursos, como vías de comprobación o depuración de los resultados obtenidos, para confirmar o, en su caso, revisar lo resuelto por el órgano de primera instancia. 
Es un mal método procesal dejar que se cometan errores en la primera instancia, imputables a la negligencia o impericia de la parte, para subsanarlos después en las instancias o trámites ulteriores, lo que supone siempre una gran pérdida para la economía del proceso (en su plena acepción de economía de dinero pero también de tiempo y de trámites). Como ejemplo a no seguir podemos recordar la antigua apelación italiana que el viejo Código consideraba una repetición del juicio de primer grado, abierta a todo tipo de alegaciones y de pruebas, cuya consecuencia era la inutilidad de la primera instancia ya que los abogados reservaban sus mejores armas para el segundo grado jurisdiccional.

En este punto, la nueva LEC española está bien orientada. Procura que el juicio de primera instancia nazca y se desenvuelva en condiciones de seguridad de que podrá dictarse al final una sentencia definitiva y de fondo. Para ello impone el control (incluso de oficio) de los presupuestos procesales y admite la subsanación de las deficiencias observadas que sean subsanables de modo que el proceso solo continúa si tales deficiencias se subsanan. Con acierto, en mi opinión, la nueva LEC trata de evitar que tengan que dictarse sentencias de "absolución en la instancia», que dejan sin juzgar la cuestión planteada y sin resolver el conflicto.

La apelación y el segundo grado jurisdiccional solo debe servir para una "revissio prioris instantiae» con la admisión de las "nova reperta" y del «ius novorum» a los casos a los que suele restringirse, vg. en la LEC española (que conserva literalmente la regulación de la LEC anterior).

Como después se dice, la sentencia que clausure un proceso de primer grado adornado con todas las garantías, si además es dictada por un juez dotado de la necesaria competencia y experiencia, es más fácil aceptar que sea ejecutada provisionalmente sin exigir al ejecutante que afiance la devolución de lo que pueda recibir por vía anticipada. En cambio, disponer la ejecución provisional de sentencias dictadas en juicios atropellados $\mathrm{y} / \mathrm{o}$ por Jueces a los que las estadísticas demuestran que les revocan a veces un $70 \%$ de sus sentencias es una temeridad que puede redundar en daños a veces irreparables y en muy grave desprestigio para la Justicia.

\section{El acceso real y efectivo a los órganos de la justicia y a las instancias procesales}

Incluso sin necesidad de plantear la «nueva instrumentalidad», hay acuer- 
do en todas partes de que los juzgados y tribunales tienen que estar abiertos para todos los que, sin distinción ni acepción alguna, tengan algún interés jurídico que defender. Esta exigencia puede decirse que formalmente ha sido lograda gracias a las Constituciones de los Estados y a los tratados, pactos y convenios supranacionales.

Pero no se trata de una proclamación formal. Lo que se pretende es que la posibilidad de acceso sea real y efectiva. Acceder a los órganos de la justicia exige disponer de medios que no están al alcance de una gran parte de los ciudadanos. En lugares de la tierra dominados por la extrema pobreza y la incultura, hablar de acceso a los jueces y tribunales suena a un "desideratum» inalcanzable. Para muchos ciudadanos puede recordarse el dicho de Portugal que recuerda "cando a Xustiça mora nos paços, tórnase inacesibelm.

Es este un largo camino con una meta muy lejana, como enseñan las investigaciones realizadas por Cappelletti y Garth, a las que me remito. ${ }^{2}$ Los logros alcanzados abren la puerta a la esperanza. Y aunque la meta se siga alejando y acaso nunca se alcance nuestro deber es caminar hacia ella sin desfallecer. Nos corresponde a los juristas llamar la atención de los gobiernos ante las dificultades de muchos ciudadanos para acceder a los órganos de la jurisdicción.

Además de suprimir toda clase de discriminaciones y de barreras debe dotarse mejor el patrocinio técnico de los más menesterosos (lo que se llama en España "la defensa gratuita" y «la defensa de oficio» y que en alguna nación de este Continente recibe el precioso nombre de «defensoría de reos pobres y ausentes").

Debe fomentarse el asociacionismo de los perjudicados cuando hay que promover macroprocesos de gran complejidad. Cada día son más frecuentes los casos que exigen las asociaciones de afectados (por ejemplo, en España los afectados por la rotura de la presa hidráulica de Tous; los lesionados por el «síndrome del aceite de colza desnaturalizado»; más recientemente, los miles de afectados por la macroestafa del "caso Banesto" del famoso financiero Mario Conde; los procesos contra grandes

2 Cappelletti-Garth, El acceso a la Justicia (la tendencia mundial para hacer efectivos los derechos), versión en español de la investigación realizada por los autores y publicada en inglés Access to Justice. A World Survey, (tradc. de M. Miranda). Con referencias a Brasil, México, 1996, cfr. Pinheiro Carneiro, Acesso à Justiça, 2a ed. 2000 (cap. 2 y el desarrollo en Parte $2^{a}$ ). 
narcotraficantes en los que a veces han querido intervenir las asociaciones de los padres de los afectados, etc.). El asociacionismo --establecido como exigencia para ejercer acciones de grupo en los casos de intereses colectivos y de intereses difusos- sin duda facilita la eficacia de la defensa en muchos casos en los que uno solo no puede afrontar la enorme carga de un proceso complicado.

\section{La solución de los conflictos como función de la jurisdicción y del proceso}

1. La doctrina dominante afirma que la función de la jurisdicción a través del proceso es determinar y aplicar el derecho objetivo que corresponda al caso concreto planteado. Chiovenda se refería a la "voluntad de la ley", una voluntad abstracta que el juez debe concretar en el caso litigioso. Después la fórmula ha sido mejorada para hacer referencia no solo a la ley sino a todo lo que sean normas jurídicas, derivadas de la ley o de las demás fuentes del derecho, así como los principios jurídicos. Otros autores hablan de concretar el «ordenamiento jurídico». En la doctrina española la mejor formulación fue hecha por Gómez Orbaneja. ${ }^{3}$ Aunque ha habido autores que han puesto como fin de la jurisdicción la aplicación de sanciones, puede decirse que atribuir a la jurisdicción y al proceso el cometido de aplicar el derecho objetivo en el caso concreto (previa su interpretación) es una dirección absolutamente dominante ${ }^{4}$ frente a los autores que han sostenido que el cometido de la jurisdicción no era aplicar el derecho objetivo sino proteger y tutelar el derecho subjetivo que el demandante plantea como lesionado.

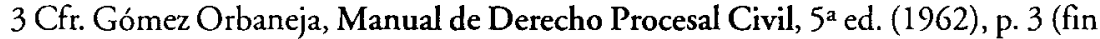
del proceso): «El fin del proceso es siempre uno solo y el mismo: la guarda y actuación de la voluntad de la ley mediante la función jurisdiccional». Y en: 4 (III): "El fin al que sirve el proceso civil, la conservación y actuación del ordenamiento jurídico privado —o la actuación de la concreta voluntad de la ley-m.

4 Prieto-Castro, Tratado de Derecho Procesal Civil, $2^{a}$ ed. Tomo I, p. 68, en la que define el proceso como una actividad jurídicamente regulada, desarrollada por el Estado por medio de sus órganos jurisdiccionales, para el ejercicio de la función jurisdiccional «de conservación del derecho objetivo» (aunque añade también «el fin de la paz jurídica y la tutela de los derechos subjetivos». 
Somos muy pocos quienes sostenemos (ya desde hace años) que debe modificarse el planteamiento y situar como función y cometido de la jurisdicción y del proceso la solución de los conflictos planteados. En Italia fue donde el genial Carnelutti construyó su famoso concepto de «litis» (construcción que, como se recuerda, él mismo modificó y en parte abandonó finalmente). En la doctrina moderna no se si existe algún autor que, además de Proto Pisani y Luiso, ${ }^{5}$ sitúe el conflicto como antecedente necesario del proceso civil y su composición o resolución como cometido de este. ${ }^{6}$ En la doctrina española apenas existen profesores sostenemos ese punto de vista como punto de partida metodológico para explicar la disciplina (el Prof. Morón y el que les habla).

2. El debate podría parecer bizantino, porque si decimos que el proceso tiene como finalidad resolver el conflicto, como quiera que el juez ha de tomar su resolución fundándose en las normas jurídicas aplicables al caso, estará siempre aplicando la ley correspondiente al caso concreto, con lo que la discusión concluiría en una tautología.

No es cierto. En otro apartado, al aludir a la nueva instrumentalidad del proceso, volveremos a remarcar la finalidad de pacificación social a que debe responder la actuación de la jurisdicción a través del proceso. Pero incluso dentro de un planteamiento tradicional de la función de la jurisdicción, la cuestión no es intrascendente.

Ilustraré mi argumento con tres ejemplos tomados de la experiencia, demostrativos de que no es igual limitarse a aplicar la ley que resolver el conflicto.

a) El primer ejemplo procede de mi directo conocimiento profesional. Hace pocos años un abogado de Barcelona tenía la sana costumbre de desplazarse al edificio de los Juzgados en bicicleta. Un día cedió una alcantarilla municipal en deficiente estado y el ciclista cayó, quedó lesionado y

5 Proto Pisani, Lezioni di diritto processuale civile, $2^{\text {a }}$ ed., 1996, pp. 4-6. No muy distante es el planteamiento de Luiso, que pone como presupuesto del proceso la producción de un «ilícito» en sentido amplio, en la situación jurídica sustancial: «un sujeto debía tener o no tener un cierto comportamiento, según las prescripciones normativas del derecho sustancial; el presupuesto constante de la tutela jurisdiccional se encuentra en la existencia de un ilícito, entendido como comportamiento diferente del deber impuesto por las prescripciones normativas»: Diritto processuale civile, I, ( $3^{\mathrm{a}} \mathrm{ed}$.), p. 7.

6 La posición dominante en la doctrina italiana puede verse recientemente expresada en Tarzia, Lineamenti del processo civile di cognizione, $2^{\text {a }}$ ed., 2002, pp. 1-5. 
la bicicleta dañada. La prensa local informó de este accidente. El interesado interpuso la correspondiente reclamación administrativa, que no fue atendida. Acudió al juez que acogió su demanda y condenó al ayuntamiento a pagarle una indemnización.

Aquí acabó el proceso. Cabe suponer que la sentencia se cumplió o ejecutó. Pero el conflicto no se resolvió porque el ayuntamiento continuó manteniendo la alcantarilla en mal estado y un tiempo después otro ciclista pudo volver a caerse y lesionarse.

b) El segundo ejemplo, lo tomo de un caso de mi experiencia profesional. En una plaza de la ciudad de Barcelona, en un barrio antiguo, confluyen una calle ancha que se va a unir con otra también ancha, a través de una calle muy estrecha, por la que apenas pueden circular dos automóviles y que es también calle peatonal.

Para proteger a los peatones el ayuntamiento había instalado una barra de hierro a lo largo de la calle, hueca por su interior (hierro de tubo). Los automóviles que procedían de la calle ancha al llegar a aquel punto habían derribado la barra de hierro y la habían roto. El tubo seguía allí pero por delante terminaba en una punta afilada que podía clavarse como un punal. Varios automovilistas habían tropezado con la barra rota resultando con daños en sus vehículos. El ayuntamiento ya había sido condenado en anteriores juicios por contravenciones. Pero el tubo seguía allí, como peligro evidente para los usuarios de la calle, y se produjo el nuevo accidente.

Un buen día una estudiante de derecho, chocó con su automóvil con la barra rota que, con su punta afilada, entró en el interior del vehículo, por el vano del motor, debajo del volante, por sitios en los que no encontró resistencia, atravesando a la conductora como si fuese una lanza, con tanta fortuna que no le alcanzó ninguna parte vital, de modo que una vez que los bomberos la llevaron al centro de asistencia para curas urgentes, pudieron extraerle la barra. Fue como un milagro que salvase su vida y que pudiesen extraerle sin complicaciones aquel tubo que le atravesaba el cuerpo de parte a parte.

Ese grave accidente no se habría producido si los jueces que conocieron de las primeras demandas, además de condenar a la indemnización, hubiesen resuelto el conflicto, ordenando a la administración realizar las modificaciones necesarias. Fue necesario que se produjese un nuevo accidente y aun así se tardó en corregir la situación. En España decimos que para que se revisen y reparen los ascensores es preciso esperar a que se caigan. 
c) El tercer ejemplo lo tomo de la conferencia que pronunció en el Congreso de Buenos Aires sobre "Jueces, abogados y medios de comunicación» (magníficamente dirigido por el Prof. Roland Arazi). La ilustre magistrada argentina Dra. Kemelmajer de Carlucci hizo referencia a los casos de accidentes sufridos por los "niños de la calle», que se caen por huecos como trampas existentes en los caminos públicos de Mendoza. En mi opinión razonó muy bien: si se aplica la ley es posible que se condene a indemnizar pero el conflicto queda sin resolver. ${ }^{7}$ Cualquier día otro niño de los que duermen bajo las estrellas volverá a pasar por allí y volverá a sufrir lesiones o daños porque el conflicto no se cerró.

Recordemos que los Códigos procesales modernos siguen regulando un interdicto o acción posesoria denominado "de obra ruinosa", con antecedentes en la jurisprudencia romana, que tiene como cometido «evitar que cause daño una obra ruinosa». En España, la regulación de la antigua LEC ha pasado a la vigente. El Art. $250^{\circ}, 6^{\circ}$, permite interponer demanda solicitando la tutela sumaria (en juicio verbal) «para que el tribunal resuelva, con carácter sumario, la demolición o derribo de una obra, edificio, árbol, columna o cualquier otro objeto análogo en estado de ruina y que amenace causar daños a quien demande». Intuitivamente, la ley pretende adelantarse al conflicto, evitando la producción de daños.

3. Hemos de ser conscientes de que el planteamiento de poner la solución de los conflictos como finalidad de la jurisdicción y cometido del proceso, está rodeado de dificultades.

La primera dificultad es la de definir el conflicto. La noción de «litis» elaborada por Carnelutti, como conflicto intersubjetivo integrado por una pretensión resistida, es insuficiente para las exigencias del futuro proceso civil. Como ha podido verse por los ejemplos propuestos, la «litis» carneluttiana quedó resuelta por la sentencia del juez acogiendo la pretensión y condenando a indemnizar. El demandante ha podido ver plenamente satisfecha su pretensión y para él ha desaparecido el conflicto. Sin embargo, pese a ello, el conflicto no desaparece y pueden volver a producirse hechos lesivos o dañosos. Y es ese conflicto el que debe desaparecer hacia el futuro. No solo se quiere indemnizar o resarcir al que ha perdido

7 Libro del "Congreso internacional sobre jueces, abogados, medios de comunicación, nuevos desafíos", organizado por el Colegio de abogados de San Isidro y por Fundesi, celebrado del 19 al 21 de abril de 2001 en Buenos Aires, bajo la dirección del profesor Arazi (la conferencia de la doctora Kemelmajer de Carlucci en p. 283 y ss., esp. p. 322). 
sus cosechas por los humos contaminantes de la chimenea de una fábrica, sino que se quiere también evitar que la fábrica siga contaminando.

Por otra parte, hemos de utilizar una noción más amplia del conflicto que nos permita comprender dentro de él no solo los conflictos intersubjetivos o "litis individuales» entre Ticio y Cayo y acaso con Sempronio, sino también los conflictos o "litis colectivas", sobre intereses colectivos y sobre intereses difusos.

4. Otra dificultad proviene de la insuficiencia de las actuales categorías de sentencias y de la actuación en el proceso civil solo a instancia de parte ("nemo iudex sine actore»).

Se haría necesario introducir un nuevo tipo de sentencia más allá de las declarativas, constitutivas y de condena. Tal nueva categoría serían las "sentencias de mandamiento", mediante las cuales el juez podría dar las órdenes necesarias para que el conflicto no quedase sin resolver.

Incluso, para que el juez, al otorgar la tutela solicitada por el particular (generalmente el resarcimiento o la indemnización) pudiera resolver el conflicto, habría que autorizarle o bien a proceder de oficio o, mejor, mediante acción ejercitada por el Ministerio Fiscal u otro órgano público. Generalmente los demandantes limitarán su petición a la satisfacción de su interés lesionado y puede haber no pocos casos en los cuales el Juez se encuentre sin demanda o pretensión a la que responder. Si no queremos convertir al Juez en un Don Quijote justiciero es necesario que un órgano público lo provea de la acción necesaria para poder resolver.

5. Pero con ello no quedarían resueltas todas las dificultades. El mayor problema me parece que es este: cuando la solución del conflicto requiere la intervención de la administración, mediante la incoación de un procedimiento que puede ser complicado y requerir diversos estudios técnicos ¿hasta qué punto puede el juez sustituir al órgano administrativo para que el conflicto se resuelva? ¿Puede servir para estos casos la concepción de Chiovenda de la jurisdicción como actividad de «sustitución»?

Imaginemos que para resolver el conflicto es necesario cerrar una fábrica contaminante, que hasta el momento la administración no ha querido clausurar. O corregir el trazado de una carretera. Los ejemplos pueden ser muchos y muy complicados. Conociendo de un proceso administrativo, ¿puede el tribunal ordenar a la administración que dicte el acto que no ha dictado, vg. que inicie la expropiación de unos terrenos o asegure un puente que amenaza ruina? Más todavía ¿puede el Tribunal sustituir al órgano 
administrativo? Los ejemplos y las dificultades pueden multiplicarse y complicarse enormemente.

Pese a las dificultades, creo que vale la pena dejar enunciado este planteamiento al menos como un tema de debate, como uno de los puntos a revisar para el futuro proceso civil, y que en todo caso, como se suele decir en los dictámenes, someto al ilustrado parecer de los asistentes a estas jornadas.

\section{Las relaciones entre derecho y proceso. La nueva dimensión de} la «instrumentalidad» del proceso

Una de las aportaciones de los procesalistas de la Escuela de Sao Paulo es la nueva dimensión de la instrumentalidad del proceso. Es obligado recordar ahora el nombre del Prof. Cándido Rangel Dinamarco, autor de un importante estudio doctrinal que lleva precisamente como título "A instrumentalidade do processo". ${ }^{8}$

Como es sabido, durante el siglo XX, uno de los problemas más debatidos y no definitivamente resuelto entre los procesalistas y los tratadistas de teoría general del derecho ha sido el de las relaciones entre "derecho" y "proceso", un problema metodológico de indudable dificultad en torno al cual se realizaron diversas construcciones, con planteamientos monistas y dualistas.

Como se recordará, Savigny y los pandektistas más que resolver el problema lo hacía desaparecer afirmando que la acción procesal no era un derecho nuevo sino que era un duplicado del derecho subjetivo o, a lo sumo, el mismo derecho subjetivo elevado al segundo grado como consecuencia de la lesión.

A una conclusión similar, solo que opuesta, llegó Kelsen aplicando su teoría de las normas jurídicas. Como todo el derecho está en las normas y la acción procesal no es más una técnica para permitir la tutela jurisdiccional, no había tampoco lugar al enfrentamiento o dualismo clásico.

También es una doctrina monista, exactamente opuesta a la anterior, la elaborada por Satta con su negación del derecho subjetivo, reducido a mero interés a proteger mediante la acción en el juicio. Una construcción

8 Candido R. Dinamarco, $A$ instrumentalidade do processo, $6^{\mathrm{a}} \mathrm{ed} ., 1998$, espc. cap. I, V, VII y IX. 
que recuerda el proceso civil romano que funcionaba no sobre derechos sino sobre acciones que podían reconocerse en el juicio.

Las posiciones mayoritarias son las dualistas, que aceptan los dos polos, el derecho y la acción, y tratan de tender los puentes de comunicación entre ellos, mediante la legitimación, la fundamentación de la demanda, etc. Los nombres de Carnelutti, Liebman, Goldschmidt, y en la doctrina española Gómez Orbaneja, Prieto-Castro y Guasp, entre otros, deben ser aquí recordados, remitiéndome a sus construcciones.

Pero tal planteamiento, pese a sus grandes implicaciones en la teoría general del derecho, es puramente formal, dirigido a explicar como se pasa de una situación jurídica material a otra procesal, y como mediante el ejercicio de la acción se introduce en el proceso una materia que en este se manufactura para ser devuelto en forma de sentencia al mundo jurídico extraprocesal.

La nueva instrumentalidad del proceso responde a un planteamiento distinto y no hace referencia solo a las relaciones del proceso con el derecho material. Dicha instrumentalidad tiene un contenido social y exige un rendimiento eficaz a las instituciones procesales, todas al servicio de esa gran finalidad última que es la "pacificación social».

Al servicio de esa gran finalidad de la paz social, se atribuyen al proceso tres órdenes de fines a alcanzar: sociales, políticos y jurídicos. Y se distingue entre un «aspecto positivo" y un "aspecto negativo». ${ }^{9}$ El aspecto positivo para exigir la necesaria efectividad del proceso, facilitando el acceso real y efectivo de todos para las peticiones de tutela jurisdiccional, removiendo los obstáculos de toda índole que impidan el libre y efectivo acceso a la jurisdicción y a las instancias procesales. El aspecto negativo, para remarcar que las formas del proceso no son un fin en sí mismas, ya que si el proceso se concibe como un instrumento de un orden jurídico justo (expresado en el derecho material) las formas tienen que ser consideradas a su vez como meros instrumentos - «instrumento del instrumento" que podría decir Calamandrei- y han de servir solo para que el proceso se desarrolle en condiciones de seguridad que permitan alcanzar una solución confiable.

En este punto, como en tantos otros, fue increíblemente avanzada la primera Ley Jurisdiccional del proceso administrativo español, del $27 \mathrm{de}$

9 Dinamarco, $A$ instrumentalidade do processo, op.cit., Cap. IX, No 35 y 36, pp. $267-$ 303. 
diciembre de 1956. Promulgada en una época nada propensa al control jurisdiccional de la Administración, supo abrir vías de fiscalización avanzadísimas (incluido el desvío de poder) y en una época dada a los formalismos, además de permitir la subsanación de los defectos procesales, afirmaba con excelente prosa:

"Se parte de un principio: que las formalidades procesales han de entenderse siempre para servir a la Justicia, garantizando el acierto en la decisión jurisdiccional y jamás como obstáculos encaminados a dificultar el pronunciamiento de la sentencia acerca de la cuestión de fondo".

Hasta tal punto es decisiva la nueva dimensión de la instrumentalidad del proceso que notables procesalistas brasileños (además de Dinamarco, Pellegrini Grinover o Watanabe, entre otros) sostienen que de las tres grandes etapas evolutivas del Derecho procesal (la primera, la del «derecho adjetivo"; la segunda la «etapa conceptual» o de elaboración de conceptos e instituciones), la última, en la que nos encontramos, es la etapa instrumental, que encierra una posición crítica en orden al rendimiento social de los conceptos y de las instituciones procesales para alcanzar aquel fin supremo de la pacificación social. ${ }^{10}$

No deja de ser significativo que esta nueva concepción de la instrumentalidad del proceso, con esa carga de justicia social y de pacificación, en lugar de surgir en Europa se haya enunciado en el Nuevo Mundo, donde las diferencias económicas y sociales y la marginalidad de grupos sociales, han aportado las circunstancias que han permitido ver $e$ incluso dramatizar el problema.

Por mi parte, no puedo dejar de señalar el temor de que a fuerza de reconocer la instrumentalidad del proceso, unida a su «desformalización", dentro de todo un proceso de «desformalización del derecho», podamos volver, desde luego por otro camino, a una situación semejante a la que llegó hasta el siglo XIX en que este árbol tan fecundo no era más que un modesto apéndice de los gruesos tratados de derecho civil, limitado a mostrar los "pasos" que había que dar para plantear y obtener la tutela de los derechos privados. En los últimos años, al menos en España, estamos

10 Araújo Cintra, Pellegrini Grinover-C.R., Dinamarco, Teoria general do processo, $17^{\mathrm{a}}$ ed., Cap. I y II, pp. 20-42. 
asistiendo a una verdadera degradación de nuestra asignatura, cuyas instituciones se divulgan en tertulias de radio y programas de televisión por verdaderos insolventes, que dogmatizan sobre todo lo divino y lo humano. La infravaloración de las formas procesales, unida a la pérdida de contacto con los autores clásicos, fundadores de nuestra disciplina, por parte de muchos jóvenes investigadores y docentes, nos sitúa ante un cuadro en absoluto optimista.

\section{De la «legitimación por la titularidad» a la «legitimación por el interés»}

En nuestros días se ha producido un ensanchamiento de la legitimación. Ya solo quedan los ecos de aquellas famosas y densísimas discusiones de la doctrina alemana e italiana (podemos recordar los nombres de Zitelmann, Betti, Garbagnati, Mandrioli, etc., que tuvieron su mejor exponente en España en Gómez Orbaneja con la no superada lección sobre la legitimación que puede leerse en su Manual). ${ }^{11}$ Se suele distinguir la legitimación material o de fondo y la legitimación procesal (en los supuestos de la sustitución) así como la legitimación derivada de la titularidad junto con la legitimación por el interés jurídico protegible.

Pero la Constitución española, en su famoso Art. $24^{\circ}, 1$, consagra como derecho fundamental a obtener la tutela judicial efectiva a favor de todos los que ejerciten sus «derechos» o «intereses legítimos». La Ley Fundamental pone en pié de igualdad el derecho y el interés legítimo garantizando para ambos por igual el derecho de acudir a los tribunales y de obtener la tutela judicial, borrando a efectos prácticos toda distinción entre las dos categorías. Quien alegue un «interés legítimo" puede exigir su protección exactamente igual que quien alegue una titularidad o «derecho". La novedad de la legitimación para la causa fundada en el interés es relativa porque ya Ihering definió el derecho subjetivo como un interés protegido.

Las consecuencias de la equiparación se han visto especialmente en el proceso administrativo (contencioso-administrativo, en la

11 Gómez Orbaneja, Derecho Procesal Civil, Manual cit. con Herce, \$11, pp. 127 141 , que a su vez hay que relacionar con $\$ 5$, y que son las dos lecciones de más denso contenido científico jamás escritas en un libro de texto procesal en España. 
pleonástica expresión española). Según la regulación legal, cuando no se ostentaba un derecho pero sí un interés, como efecto reflejo de la resolución que se pudiera dictar en el proceso, el titular de ese interés puede intervenir en el proceso pero no como parte sino (solo) como «coadyuvante», en una posición subordinada a la administración. Pero hoy, al admitirse el interés legítimo como categoría legitimadora autónoma por el Art. $24^{\circ}, 1$, de la CE., la figura del coadyuvante ha perdido utilidad, toda vez que ese portador de un interés legítimo puede actuar en el proceso al mismo nivel que las partes legitimadas por la titularidad del derecho.

La apertura de la legitimación al interés legítimo evidencia el cambio producido que no ha podido menos que reconocerlo también la nueva ley reguladora del proceso civil. En efecto, la nueva LEC establece en el Art. $10^{\circ}$ que "serán considerados partes legítimas quienes comparezcan y actúen en juicio como titulares de la relación jurídica u objeto litigioso". Es este el planteamiento clásico.

Pero poco después el Art. $13^{\circ}$ tiene que disponer: «mientras se encuentre pendiente un proceso, podrá ser admitido como demandante o demandado, quien acredite tener interés directo y legítimo en el resultado del pleito».

La expansión de la legitimación a todo titular de interés legítimo facilita notablemente la tutela en muchas situaciones complejas.

\section{Poderes e iniciativas probatorias del juez}

1. El «juez espectador», en un papel puramente pasivo, de receptor de alegaciones y pruebas, ya lo escribió hace muchos años el Maestro AlcaláZamora, no sirve. No sirve para el proceso penal pero tampoco para el proceso civil.

Tampoco sirve hoy el "juez inquisidor", que pretende investigar las relaciones del derecho privado como si fuesen crímenes contra la sociedad. Menos todavía el «juez pesquisidor», una especie de Don Quijote (hoy enfermo no por leer excesivas novelas de caballería sino acaso por las injusticias que vemos cada día) que vaya por la vida lanza en ristre decidido a corregir y enmendar entuertos ajenos. El derecho y el proceso están presentes en la obra inmortal de Cervantes y siempre ha habido Jueces que han imitado a ese modelo del Quijote justiciero. 
Como se sabe, es este uno de los problemas más delicados de toda la teoría del proceso, lo que explica que acostumbre a ser un asunto recurrente en casi todos los congresos. ${ }^{12}$

2. Como es sabido, tradicionalmente las facultades e iniciativas probatorias del juez se han resuelto mediante el principio dispositivo (entendido no como disposición de los derechos e intereses en el proceso sino como disposición de la prueba). Es obligado punto de referencia la polémica sostenida hace años en la doctrina y, especialmente, el ensayo de Liebman gráficamente titulado «Fundamento del principio dispositivo". ${ }^{13}$

Siguiendo esta dirección doctrinal, el Juez del proceso civil está vinculado a la prueba de parte de modo que resultaría inquisitivo un proceso civil en el que el juez pudiera separarse de la prueba de parte: «iudex iudicare debet secumdum iuxta allegata et probata partium, et non secundum suam constientiam».

El criterio tradicional había sido sometido a revisión crítica por Guasp en un ensayo titulado «juez y hechos en el proceso civil» que dada la época en que se publicó hubo quien pudo ver en él un planteamiento político propio del momento, más que un planteamiento doctrinal y técnico.

Más hacia nuestros días ha sido Cappelletti quien, entre otros, ha defendido que el proceso civil es un instrumento público, que, aunque tenga como objeto una relación de derecho privado, es un instrumento público, está sometido a normas de derecho público o necesario, y cuya utilización se encomienda a un juez del Estado, que no puede quedar constreñido por las conveniencias particulares de los litigantes. En consecuencia, Cappelletti propuso distinguir en el famoso aforismo dos partes a diferenciar: una, la que ordena que el juez dicte sentencias «según lo oportunamente alegado" por las partes; otra, desvinculando al juez en cuanto a la prueba de la iniciativa de las partes, pudiendo introducir prue-

12 Como es lógico, en torno a una cuestión fundamental y polifacética del proceso moderno, la bibliografía producida ha sido y es muy numerosa. Para una exposición de las diversas posiciones doctrinales, las cuestiones y principios implicados, con su valoración crítica cfr. Cavallone, Il giudice e la prova nel processo civile, Pavía, 1991.

13 Liebman, «Fondamento del principio dispositivo», en: Estudios para el profesor Jemolo, así como en la «Rivista di diritto processuale» e incorporado al volumen del autor: Problemi del processo civile, Milano, 1962, p. 3 y ss. 
bas de oficio para comprobar la realidad o veracidad de las alegaciones realizadas. ${ }^{14}$

No se puede negar que esta última tendencia está hoy en alza. Ha ido ganando terreno en el proceso laboral o social y en el proceso administrativo. ${ }^{15}$

En la intervención probatoria del juez conviene distinguir dos planos bien distintos. El primero se refiere a las potestades del juez para intervenir en la práctica de todas las pruebas, solicitando aclaraciones, precisiones o realizando preguntas sobre extremos no planteados por las partes a los peritos, a los testigos y a los propios litigantes. El segundo se refiere a las iniciativas probatorias que por su propio oficio puede adoptar el juez, supliendo o completando las iniciativas probatorias de las partes (vg. llamando a testigos no propuestos por las partes, solicitando nuevos interrogatorios de los litigantes, acordando recibir informes periciales o reclamando el envío de documentos). Así como las facultades probatorias del primer grupo no se discuten y nadie defiende al «juez espectador», neutro, pasivo y mudo, atento solo a lo que ante él pasa por exclusiva iniciativa de las partes, las iniciativas del segundo grupo son muy discutidas. Y es lógico que así sea porque encierran el peligro de que aparezca el juez inquisidor en asuntos particulares o privados de los ciudadanos. Recordemos de nuevo a Liebman cuando refutó a nuestro Guasp (en mi opinión convincentemente) y concluyó que sería inquisitiva la actuación de un juez en el proceso civil si no está vinculado por la prueba de parte.

3. Para este problema ciertamente difícil, el derecho español elaboró una solución feliz y eficaz. Fueron las «diligencias para mejor proveer». Su primera regulación se encuentra ya en varias leyes de la Partida III. Su fundamento nunca fue dogmático sino de puro «buen sentido». Al juez civil no le pedimos solo que dicte sentencias sino que dicte sentencias justas. Con más razón esta petición encuentra fundamento en un Estado de derecho. Pero para dictar sentencias justas el Juez necesita conocer la realidad de los hechos (deliberadamente omito hablar de «verdad», por ser un concepto mucho más comprometedor). Conservadas durante siglos y utilizadas asiduamente por los jueces y tribunales cuando consideraban que era fundamental contrastar un determinado dato, las diligencias para mejor proveer alcanzaron su mejor regulación en los arts. $340^{\circ}$ $342^{\circ}$ de la derogada Ley de Enjuiciamiento Civil . La redacción dada por la Ley de Reforma de 1984, armonizó la necesidad de conceder al juez iniciativas probatorias para acordar de oficio completar la prueba aporta- 
das por las partes en los cinco supuestos recogidos en el Art. $340^{\circ}$, con el derecho de las partes a intervenir siempre en la práctica de dichas pruebas de oficio, realizando después alegaciones críticas sobre su resultado, y adoptando cautelas para evitar que tales diligencias pudieran utilizarse no para «mejor proveer» sino - como se decía con ironía en la práctica forensepara «mejor dilatar» el pronunciamiento de la sentencia ( $c f r$. arts. $341^{\circ}{ }_{-}$ $342^{\circ}$ ). Con esta institución los juristas españoles podíamos afirmar sin temor a equivocarnos que nuestros jueces siempre podían dictar sentencias justas y si no lo hacían no era porque la ley se lo impidiese sino por alguna negligencia o desidia personal, que podía tener su rectificación en la segunda instancia. Las diligencias probatorias así acordadas han servido en numerosísimos casos para resolver en justicia supliendo los jueces y tribunales las omisiones o deficiencias probatorias de las partes (frecuentemente debidas a descuido o impericia). Y su utilidad fue reconocida en Hispanoamérica, donde fue incorporada a sus Códigos procesales, de modo que un juez argentino está tan familiarizado con las diligencias para mejor proveer como lo estaba un juez español.

La nueva LEC 1/2000 mantiene, e incluso ha acentuado, las facultades del juez en la práctica de la prueba propuesta por las partes, pudiendo pedir aclaraciones o explicaciones a los litigantes, testigos y peritos, examinando por sí mismo los documentos.

Pero en cuanto a la prueba de oficio, ha sustituido las seculares «diligencias para mejor proveer" por las ahora llamadas "diligencias finales", advirtiendo en la Exposición de Motivos que no se trata de un mero cambio de nombre sino de algo muy diverso. La nueva LEC, inspirada en una concepción ultraliberal del proceso civil, propia del siglo XIX, pretende ser fiel sin fisuras y a ultranza, al principio de aportación de parte de las pruebas (la «Verhandlungsmaxime») y restringe a hipótesis muy concretas las iniciativas probatorias por oficio del propio Juez. La nueva regulación se encuentra en el Art. $435^{\circ}$, que con una prosa de la peor

14 El pensamiento de Cappelletti, en el cual se observa una evolución hasta convertirse en la doctrina italiana, seguramente en el más destacado crítico del principio dispositivo, se refleja en: La testimonianza della parte nel sistema dell'oralità, Milano, 1962, I, p. 318 y ss. y más tarde en: Processo e ideologie, Bolonia, 1969, p. 155 y ss. así como en otros trabajos referidos en este volumen.

15 Cfr. el reciente volumen de Morello, La prueba (tendencias modernas), Buenos Aires, 2ed., 2001, especialmente p. 37 y ss. y 63 y ss. 
calidad, ${ }^{16}$ en medio de confusiones y contradicciones gramaticales inadmisibles, en una reciente ley promulgada para regir el proceso civil del siglo $\mathrm{XXI}$, ha supuesto una regresión histórica verdaderamente increíble, que por chocante que pueda resultar apenas ha levantado críticas de la doctrina, ya que solo algunos no hemos dudado en censurar semejante retroceso histórico. ${ }^{17}$

El legislador cree que el juez puede anticiparse a la eventual necesidad de completar la prueba advirtiendo a las partes en la audiencia previa al juicio que falta una determinada prueba, advirtiéndolo así a los litigantes (bajo pena de no poder practicarse después las pruebas no propuestas como diligencias finales). Pero el legislador padece un triple error. En primer lugar, en ese momento de la audiencia, al final de la cual se propone la

16 Nada mejor que confrontar el Art. $340^{\circ}$ de la derogada LEC de 1881, regulador de las «diligencias para mejor proveer» (según la redacción dada por la Ley de Reforma Urgente 34/1984), que permitía a los Jueces y Tribunales acordar, "antes de pronunciar su fallo", cinco diligencias de prueba, cuya práctica en absoluto podía comprometer su imparcialidad, y que necesariamente habrían de practicarse con intervención de las partes, a las cuales correspondía alegar después (arts. 34\%-342\%), comparándolo con lo que ahora establece el Art. $435^{\circ}$ de la nueva LEC, pensado solo para el juicio ordinario (; como si en los demás juicios el problema del Juez no fuese el mismo!) y pensado solo para el Juez unipersonal, no para el Juez colegiado ( $i$ como si la dificultad no pudiese plantearse a los Tribunales exactamente igual que a los Jueces de primer grado!). En el apartado 1 , mientras la regla $1^{a}$ dice "no se practicarán", la $3^{\text {a }}$ dispone "también se admitirán", mientras que la $2^{\text {a }}$ no indica el sentido afirmativo o negativo. El mejor ejemplo de una redacción lamentable es, no obstante, el No 2, del siguiente tenor literal: «Excepcionalmente, el tribunal (se refiere al Juez, al que la nueva LEC llama siempre tribunal) podrá acordar de oficio o a instancia de parte (previamente el No 1 dijo que "solo a instancia de parte podrá el tribunal acordar [...]) que se practiquen de nuevo pruebas sobre hechos relevantes, oportunamente alegados, si los actos de prueba anteriores no hubieran resultado conducentes (?) a causa de circunstancias ya desaparecidas e independientes de la voluntad y diligencia de las partes, siempre que existan motivos fundados para creer que las nuevas actuaciones permitirán adquirir certeza (?) sobre aquellos hechos". Dejo a los ilustres colegas y lectores de Iberoamérica valorar críticamente la nueva institución y el precepto transcrito.

17 En este punto se me permitirá que evoque la obra El jurista y el simulador en la que el jurista mexicano traza magistralmente los caracteres del jurista y del que simula serlo. En España, en una época de libertad y de democracia, abundan más los simuladores que los juristas. Hemos visto a profesores que han actuado exactamente al contrario de cómo predicaban hace diez o quince años y vemos como hoy se defienden posiciones absolutamente contrarias a las que entonces se defendieron. "París bien vale una misa» y para algunos también lo vale disfrutar de alguna prebenda por efímera que sea. 
prueba, no siempre el juez está en condiciones de saber si la prueba ofrecida por las partes cubre todas las afirmaciones realizadas en la demanda y en la contestación. En segundo lugar, no es posible anticipar cual será el resultado de las pruebas propuestas y sin conocer su resultado no se puede saber si sería preciso practicar alguna prueba omitida bajo la esperanza de que sean suficientes las propuestas. Y en tercer lugar, sobre todo, cuando el juez puede advertir la ausencia de una prueba necesaria, que convendría suplir o completar para resolver en justicia, es cuando se encierra con los autos del proceso para estudiar como debe ser su sentencia justa.

4. Lo más chocante del legislador español es que mientras recortó drásticamente las iniciativas probatorias para el juez en el proceso civil, en una ley de la misma época, promulgada por el mismo Parlamento y a iniciativa del mismo gobierno, estableció todo lo contrario en cuanto a las potestades probatorias del Juez en el proceso administrativo. En efecto, tan solo un año antes de la nueva LEC - la Ley No $1 / 2000$ - se había promulgado la nueva Ley Jurisdiccional para el proceso contencioso-administrativo - la Ley No 29/1998, del 13 de julio-, en la que se mantiene inalterada la iniciativa probatoria que ya había establecido su antecesora, la Ley Jurisdiccional del 27 de diciembre de 1956 (Art. 75), permitiendo al juez no solo intervenir activamente en la práctica de todas las pruebas sino acordar, por su propia iniciativa, la práctica de todas aquellas que considere necesarias para dictar sentencia acertada.

El Art. $61^{\circ}$ de la vigente LJCA dice así:

«1. El juez o tribunal podrá acordar de oficio el recibimiento a prueba y disponer la práctica de cuantas estime pertinentes para la más acertada decisión del asunto".

«2. Finalizado el período de prueba y hasta que el pleito sea declarado concluso para sentencia, el órgano jurisdiccional podrá también acordar la práctica de cualquier diligencia de prueba que estimare necesarian.

El artículo sigue regulando la garantía de la intervención de las partes en la práctica de las pruebas acordadas de oficio y su derecho a alegar y valorar críticamente su resultado.

Dos leyes impulsadas y preparadas por el mismo Gobierno, aprobadas por el mismo Parlamento y a muy poca distancia de tiempo, con una regulación absolutamente contrapuesta! ¿Por qué puede un Juez en un 
proceso administrativo tomar iniciativas probatorias que no se permiten al juez en el proceso civil?

La situación es tan flagrantemente contradictoria que no puede tener ninguna explicación racional, que tampoco ha sido ofrecida por quienes tenían el deber de hacerlo.

\section{Poderes de coerción judicial}

De igual modo que si queremos que el juez dicte sentencias justas es necesario que le otorguemos los poderes necesarios para la cognición judicial (obviamente dentro del contradictorio) si pretendemos que el proceso sea eficaz, es necesario que concedamos al Juez los poderes de coerción necesarios.

Entre tales poderes de coerción están las «astreinte» o multas coercitivas para obligar al cumplimiento de lo ordenado en las resoluciones judiciales; las "intimaciones" o requerimientos coercitivos; las "injunciones", tan eficazmente utilizadas en el proceso civil anglosajón; e incluso - aunque pueda ser mucho más discutible - la incorporación de la figura inglesa de la "desobediencia al Tribunal" ("comptem of Cort") con todas las consecuencias que ello comporta en orden a la actuación disciplinada de las partes y su deber de buena fe y lealtad al Tribunal.

La nueva LEC española ha avanzado en esta orientación. Ha incorporado las «astreinte», en su modalidad francesa (ad. ex. Art. 589). Dispone de requerimientos e intimaciones judiciales, algunos incluso bajo la amenaza de desobediencia penal al tribunal. No ha incorporado las injunciones. En cambio, permite dirigir advertencias e incluso imponer multas sancionadoras a los litigantes y a los propios Abogados, si en el proceso no son diligentes en el cumplimiento de sus deberes o si actúan con mala fe (Art. 168\%).

La experiencia dirá si los nuevos medios de coerción son suficientemente eficaces.

\section{La ejecución provisional de la sentencia}

1. La ejecución provisional de las sentencias sometidas a recurso se ha aceptado en los Códigos procesales (y no en todos) siempre que el ejecutante afiance la devolución de lo que provisionalmente reciba en el caso 
de que la sentencia sea revocada en todo o en parte. A esa conclusión se llegó en España en 1984 al promulgarse la Ley No 34/1984, reformando el antiguo Art. $385^{\circ}$ de la LEC. La ejecución así regulada solo era eficaz cuando el vencedor era una entidad bancaria o financiera para la cual avalar no suponía dificultad alguna. Pero cuando el vencedor era un ciudadano sin grandes recursos financieros, la dificultad estaba en que para recibir lo que la sentencia le daba, el juez le exigía afianzar previamente (generalmente por medio de un aval bancario) una cantidad superior al cien por cien de lo que podía recibir. Por si fuese poco, a veces, después de constituir el aval, con el sacrificio que cabe imaginar, no siempre recibía lo que esperaba por las dificultades que se oponían a la ejecución, por las dificultades de realizar los bienes del condenado o por frecuentes dilaciones de los juzgados.

En estas circunstancias, la ejecución provisional de las sentencias no firmes, aunque admitida con gran amplitud por el nuevo Art. $385^{\circ}$ de la LEC, no era una medida eficaz.

2. La nueva LEC ahora vigente ha sido en este punto indudablemente audaz. Queda por ver si además de audaz no ha sido temeraria. Una de las novedades más utilizadas en la publicidad de las bondades de la nueva ley fue precisamente la de que «se podrían ejecutar, sin exigir fianza al vencedor, las sentencias de los juzgados o de las audiencias, aunque estuviesen recurridas", dotando así de eficacia a la justicia y ahuyentando los recursos infundados o meramente dilatorios.

El legislador toma como argumento que si se pueden ejecutar las resoluciones de la administración, aunque no sean firmes, con la misma o superior razón se ha de admitir que puedan ejecutarse las sentencias judiciales aunque no hayan ganado firmeza. Además, alude a que las estadísticas no acreditan que el número de sentencias de primer grado que se revocan sea tan elevado como se suele decir.

Algunos hemos expresado nuestras lógicas reservas y temores.

En contra de lo que afirma la exposición de motivos de la ley, no sirven las estadísticas sobre el número global de sentencias que se revocan porque los propios magistrados de Cámaras de apelación (nuestra Audiencia Provincial) han expresado públicamente que mientras hay jueces a los que se le revocan muy pocas sentencias a otros se les revocan más de un $50 \%$ e incluso un $70 \%$. En todo caso, no es una cuestión solo de tantos por ciento de revocaciones, ya que el problema capital es quien responde frente al ejecutado en los casos en los que la ejecución haya resultado improcedente. 
3. Como se ha escrito recientemente por autores que han realizado una investigación comparada, la ejecución provisional de las sentencias en Europa es una institución «isolata». Solo Italia y ahora España la admiten y todavía carecemos de la experiencia necesaria para poder emitir una opinión solvente.

No obstante, en Italia la Corte de Apelación puede parar la ejecución provisional. En España, la regulación legal abre varias vías para impedir o para detener la ejecución, acudiendo a los conceptos jurídicos indeterminados de los que se sirve y que puede hacer valer el ejecutado: la «imposibilidad» o la «extrema dificultad» de volver las cosas a su estado anterior si la ejecución va adelante y después la sentencia es revocada ( $c f r$. arts. $528^{\circ}$, $2^{\circ}, 2^{\mathrm{a}}$ y $3^{\mathrm{a}}$ ). En todo caso, quien ejecute provisionalmente una sentencia debe calcular las posibilidades de que pueda ser revocada porque en caso de que así suceda, la ejecución provisional resultara para él, si es solvente, un pésimo negocio al tener que devolver principal, intereses, costas y daños y perjuicios ( $c f r$. arts. $533^{\circ}-534^{\circ}$ ).

En España, muy recientemente, a partir del verano de este año ya se está poniendo "el grito en el cielo" por algunos sectores afectados por la ejecución provisional. El semanario "El Siglo», de la órbita de "El País", acaba de publicar todo un número especialmente dirigido a combatir la ejecución provisional, porque las sentencias de condena provisionalmente ejecutadas contra dicha revista, obligándole a pagar las indemnizaciones establecidas, colocan a la empresa al borde de tener que cerrar. El semanario advierte con iniciar una cruzada contra este aspecto de la ley. Los medios de comunicación se caracterizan por dar muy escasa importancia a las leyes procesales cuando se plantean o discuten, porque tienen muy escaso valor como "noticia». Cuando se estabas discutiendo las grandes novedades de la nueva LEC, jamás un medio de comunicación informó de lo que se debatió en los seminarios y jornadas celebradas, en las que frente a la doctrina oficialista, algunos no hemos ahorrado críticas que nos parecieron fundadas. Nunca nos abrieron las páginas de los periódicos para expresar nuestras opiniones. Esos debates, ya se sabe, «no venden" $y$ "no son noticia». Ha habido que esperar a que la novedad les toque a los "medios" para que alcen su voz y dediquen papel impreso a algo que de no afectarle a sus empresas no les importaría lo más mínimo. Y no deja de ser curioso que se quejen los que acaso tienen menos razón para alzar su voz, porque el caso de las condenas a la prensa es precisamente uno de los supuestos más paradigmáticos para que proceda la ejecución 
provisional sin afianzamiento. Ya que el riesgo de revocación está demostrado que es mucho menor y lo verdaderamente escandaloso es que se difame y se injurie irresponsablemente o se ataque la privacidad de las personas, porque de ese modo se pueden vender acaso dos ediciones de la revista, con la seguridad de que si tienen que pagar será al cabo de siete u ocho años, cuando la empresa responsable haya agotado los recursos.

4. El riesgo, como ya se comprende, estriba en las ejecuciones provisionales promovidas por vencedores insolventes. ¿Quién responderá ante el ejecutado de las consecuencias de la ejecución improcedente si la sentencia es revocada? En España se está estudiando la posibilidad de exigir responsabilidad al Estado, que ya responde por los errores judiciales en determinadas circunstancias.

La solución ideal —como ha señalado Berizonce- ${ }^{18}$ sería socializar el riesgo, creando un "fondo" público para estos casos de un modo análogo al fondo de garantía salarial, para cubrir los casos de quiebra o insolvencia de los empresarios, o al fondo de garantía de riesgos de la circulación, para garantizar a las víctimas de accidentes causados por conductores que circulaban sin el preceptivo seguro. Pero los gobiernos se encuentran con muchas peticiones de socialización. En España tenemos una maravilla social que es la seguridad social (creada y desarrollada durante el franquismo, todo hay que decirlo) de la que ya no se dispone en América Latina ni tampoco en Norteamérica. Cuesta mucho mantenerla con la absoluta gratuidad actual. Pero es el primer gran elemento del «Estado de bienestar». Tenemos también (y es otra creación del franquismo) el «Fondo de Garantía Salarial» para asegurar el pago de los haberes que los trabajadores no han percibido cuando sus empresas quiebran o desaparecen. Y (también en la época franquista) se creó y funciona aún el «Fondo de Garantía de riesgos de circulación", que garantiza la indemnización de las víctimas de los accidentes de tránsito, cuando el responsable no iba cubierto por un seguro. Ya son muchos fondos. Pero hoy las mujeres separadas piden un fondo que les pague las pensiones que sus maridos separados no atienden. Y también los maridos dicen que si pagan las pensiones señaladas por los jueces no les queda a ellos para vivir. Con frecuencia son los hijos los que sufren las consecuencias. Ante esas demandas, no veo que el "Welfare state» español vaya por el momento a cubrir esta demanda.

18 Berizonce, «El Juez y la magistratura», en: Tendencias en los albores del siglo XXI, relatorio general al Congreso de Viena de 1999, Buenos Aires, 1999. 
5. Hemos de volver a la primera premisa de los instrumentos necesarios para un futuro proceso civil. Con buenos jueces, la ejecución provisional no produce tantos temores. Los profesionales conocemos a jueces de los que se sabe de antemano que es muy difícil que le revoquen sus sentencias, a la vez que conocemos a otros a los se le revocan en un número muy elevado. Lo acaba de decir así el Presidente de una de las Audiencias Provinciales de Cataluña en el seminario recientemente celebrado en Barcelona sobre problemas de la organización jurisdiccional ante el proceso del siglo XXI. Hay algunos jueces de primera instancia ante cuyas sentencias los Magistrados de apelación proceden como si no se hubiese juzgado en primera instancia y más que revisar la sentencia juzgan de nuevo.

\section{Ejecución más eficaz}

1. La ejecución de las sentencias debe seguirse ante el mismo juez y en el mismo proceso. Y los títulos ejecutivos deben contar con procesos rápidos para su efectividad.

Así ha sido tradicionalmente en España. Una vez firme la sentencia, la ejecución se solicitaba por medio de un sencillo escrito que se presentaba ante el mismo juez que había dictado la sentencia, el cual procedía a la ejecución en los mismos autos del proceso. La ejecución, sin perjuicio de su autonomía conceptual como proceso, a los efectos prácticos era como una nueva etapa que en los mismos autos seguía a la etapa de conocimiento, para ejecutar la sentencia firme dictada.

La nueva LEC 1/2000 vino a crear, entre otras, una complicación innecesaria. Solo por poner en solfa legislativa discutibles posiciones doctrinales, la nueva ley ha convertido la ejecución de la sentencia en un nuevo proceso, exigiendo para su incoación una nueva demanda, la «demanda ejecutiva" (Art. 549\%), imponiendo además un novedoso "plazo de espera" de veinte días (posteriores a la notificación de la resolución) para poder interponer dicha demanda (Art. 548 ). Lo que antes era un simple escrito sencillo y de puro trámite, ahora ha sido sustituido por una demanda formalizada, con las innecesarias dilaciones y complicaciones que de ello se derivan. Y eso se ha hecho en una ley que toma como uno de los principios inspiradores el de la tutela del crédito.

2. En cambio, la nueva LEC ha introducido muchas mejoras en la ejecución, para hacerla más eficaz. Se ha incorporado la «manifestación de 
bienes» bajo juramento y con la posible aplicación de multas en caso de incumplimiento o cumplimiento defectuoso de tal obligación (Art. 589). Se han admitido nuevos medios para la «localización de bienes del deudor", mediante iniciativas oficiales del Juzgado (Art. 590\%). Se ha establecido un deber general de colaboración y un deber de colaboración específico de las entidades públicas y privadas (Art. 591\%). Se ha regulado mejor la subasta, para hacerla más ágil y eficaz (arts. $643^{\circ}-649^{\circ}$ y $666^{\circ}$ y ss.), admitiéndose la realización de los bienes por persona o entidad especializada (Art. 641\%). Se ha facilitado la transmisión del bien con la directa inscripción en el registro de la resolución judicial aprobando el remate (Art. 674ㅇ․ Se ha introducido por vez primera en nuestro derecho un procedimiento incidental específico para lanzar a los ocupantes del inmueble sin título o con título que no ampare su ocupación (arts. $661^{\circ}$ y $\left.675^{\circ}\right)$. Se ha fortalecido la ejecución de obligaciones de hacer o de no hacer, contemplando la imposición de multas sancionadoras, bajo la modalidad de las «astreinte" (arts. $701^{\circ}-711^{\circ}$ ) que, aunque con algunas imprecisiones, cabe entender que se refieren a la modalidad francesa de la institución.

3. En España disponíamos también de un juicio ejemplar de tutela ejecutiva sumaria, que era además el juicio que mejor funcionaba en la práctica. El famoso «juicio ejecutivo», con un prestigio y un perfeccionamiento de siglos, que había pasado a Hispanoamérica, donde se han escrito excelentes tratados y monografías sobre él. ${ }^{19} \mathrm{Ha}$ sido apedazado o troceado, llevando la ejecución de unos títulos a la ejecución de la sentencia firme y la de otros al juicio cambiario (arts. $556^{\circ} \mathrm{v} .557^{\circ}$ y $559^{\circ}$, en cuanto a la ejecución de títulos jurisdiccionales o arbitrales y los arts. $819^{\circ}$ $827^{\circ}$ en cuanto al juicio cambiario). Se ha privado a nuestro derecho de una de las instituciones de creación autóctona de indudable prestigio y razón de ser, como puso de manifiesto Liebman en su famosa relación al Congreso de Viena de $1953 .{ }^{20}$

19 Bustos Berrondo, Juicio ejecutivo, La Plata, $6^{\circ} \mathrm{ed}$, 1993 y bibliografía que se cita, que comienza con un excelente y documentado prólogo de Morello, en el que expone el origen y la evolución del juicio ejecutivo y los problemas doctrinales que en torno a él se planteaban en la doctrina española (que el prologuista conoce con la perfección de la que siempre hace gala).

20 Liebman, "Problemi [...]", op.cit., en: I presupposti dell'esecuzione forzata, pp. 343-354. Maravilla constatar no solo el perfecto conocimiento del eminente Maestro sobre el juicio ejecutivo español sino como con su consabida claridad expositiva contrasta 
4. Frente a ese desacierto de la nueva LEC. hay que anotar entre sus adelantos notables la introducción del "juicio monitorio", tantas veces reclamada inútilmente por la doctrina y que solo la torpeza del legislador (entonces era el Gobierno socialista) dejó de introducir al promulgar en 1984 la extensa "reforma urgente» de la antigua LEC. Todavía no existe experiencia suficiente sobre el funcionamiento de este nuevo proceso, concebido finalmente en la regulación legal como juicio de cognición plenaria aunque rápida gracias a la técnica de la inversión del contradictorio, como explicó en su día Calamandrei.

Sin duda el juicio monitorio será de gran utilidad práctica, aunque no sea prudente aceptar las esperanzas exageradamente optimistas expresadas por los más recientes estudiosos.

5. En Europa se viene estudiando la creación de un "título ejecutivo europeo», para facilitar la ejecución de créditos transnacionales, que hoy por hoy no cruzan las viejas fronteras con la misma facilidad que las mercancías. Se han celebrado varios coloquios -en dos de los cuales he tenido el honor de participar- $y$ ya se han publicado algunos estudios valiosos. ${ }^{21}$ Uno de los puntos que centran el debate es el de si el camino a seguir para la creación del título ejecutivo europeo debe ser el de una directiva, el de la armonización u homologación de los procedimientos de ejecución en los países de la Unión Europea.

Es indudable que el auge y la facilitación de las transacciones transnacionales facilitadas en grandes áreas económicas y jurídicas, como sucede hoy en Europa, exige facilitar la ejecución de títulos de crédito creados en cualquier país integrante de dicho espacio, así como también la realización de las sentencias legalmente dictadas por los tribunales de los estados miembros.

las «tres soluciones que las legislaciones de Alemania, Italia y España ofrecen para un mismo probleman y de las que dice colocan al acreedor y al deudor en posiciones no tan alejadas entre sí.

${ }^{21}$ Cfr. Tarzia, Prospettive di armonizzazione, op.cit., p. 847 y más recientemente L'ordine europeo del processo civile, Rivista di Diritto Processuale, 2001-4, p. 902 y ss. especialmente $\mathrm{N}^{\circ} 11, \mathrm{y}$ "Harmonisation ou unification transnationale de la procedure civile» (Relación general al Congreso Internacional de Viena, 1999), en: Rivista di diritto internazionale privato e processual, oct.-dic. 2001 , No 4, p. 869 y ss. 


\section{Nuevas categorías de sentencias}

Se ha expresado por destacados procesalistas iberoamericanos que la clasificación tripartita de sentencias que tradicionalmente venimos utilizando y con la que enseñamos la asignatura (sentencias declarativas, constitutivas y de condena) debe completarse con una distinción de cinco categorías de sentencias, añadiendo a las tres clásicas las "sentencias de mandato" («sentencias mandamentales»), para dirigir una orden o mandato a otro órgano del Estado o a particulares para hacer cumplir eficazmente los pronunciamientos jurisdiccionales, y las "sentencias ejecutivas" lato sensu (una sentencia de cognición con eficacia análoga a la sentencia de condena pero que además legitiman la ejecución sin necesidad de nuevo proceso). Estas permiten que en un mismo proceso se desarrolle la actividad cognitiva, se concrete en la sentencia, y la actividad de ejecución, sin necesidad de interponer nueva demanda ni ejercitar nueva acción ni realizar nueva citación del obligado, uno o de cuyos ejemplos en las legislaciones iberoamericanas son las acciones restitutorias de posesión en casos de despojo. ${ }^{22}$

Comparto esta opinión. Sin las nuevas formas de sentencia el futuro proceso civil no podrá cumplir las nuevas finalidades que reclamamos. Por ejemplo, las sentencias de mandamiento son las que pueden servir para hacer que desaparezca el conflicto que ha dado lugar al proceso y que el fin del proceso no se limite a la condena a indemnizar al demandante.

\section{Nuevas técnicas de tutela}

Disponiendo de los buenos jueces exigidos como primera premisa, el futuro proceso civil debe disponer de un elenco de nuevas técnicas de tutela creadas o perfeccionadas en las últimas décadas del siglo XX.

a) El futuro proceso civil debe incorporar un buen sistema de "tutela cautelar", que permita el aseguramiento de todas las situaciones jurídicamente legítimas. Doctrinalmente se ha adelantado mucho y hay que hacer aquí homenaje a las aportaciones de los procesalistas de Iberoamérica,

22 Cfr. Araújo, Pellegrini Grinover y C. R. Dinamarco, Teoria general do processo, op. cit., No 192, 196 y 201, pp. 302, 305, 312-314. 
que han superado incluso a los europeos. La posición más avanzada y defendible me parece la de reconocer a nivel doctrinal y legal la tutela cautelar, la acción cautelar (como ya enseñó Chiovenda con un siglo de anticipación. Configurando la acción cautelar como acción de puro contenido procesal), y reconocer el proceso cautelar como instrumento para hacerla efectiva (con los procedimientos cautelares para acordar, modificar $\mathrm{o}$ alzar las medidas solicitadas).

La nueva LEC 1/2000 ha significado un progreso respecto de la situación anterior en varios aspectos. En el aspecto sistemático ha sido un adelanto porque ha ordenado toda la materia cautelar en un mismo lugar de la nueva ley y ha unificado todos los procedimientos antes dispersos. En el plano de la eficacia, porque ha admitido nuevas figuras de cautela con una cláusula abierta o norma en blanco para cautelar situaciones no previstas expresamente merecedoras de aseguramiento (una norma que recuerda el famoso Art. $700^{\circ}$ del C.p.c. italiano), a la vez que ha protegido a los afectados por las medidas, para que puedan solicitar su revisión, modificación y alzamiento así como su sustitución por una fianza con análoga función asegurativa. Se debe recordar que en el Borrador y en el Anteproyecto del Gobierno (antes de su remisión al Parlamento) el planteamiento de las medidas cautelares era increíblemente retrógrado, porque únicamente podían ser cauteladas las sentencias de condena, no las declarativas ni las constitutivas, debido a que los autores que prepararon el texto seguían aferrados al punto de vista doctrinal, largamente superado en todo el mundo. De que las medidas cautelares están preordenadas para asegurar la ejecución, de modo que donde no haya sentencia que ejecutar no procede cautela alguna. Todos los preceptos del futuro Código se referían siempre a "sentencia de condena». Gracias a unas Jornadas confrontativas, con los profesores autores del Borrador y del Anteproyecto, celebradas en Madrid, auspiciadas y organizadas por la Asociación de usuarios de banca (que fueron las únicas organizadas con planteamiento de verdadero debate confrontativo sobre el Anteproyecto), en las cuales se estableció la dialéctica (con igualdad de armas) entre un ponente defensor del texto y un contraponente que expresó las críticas (cualidad que en materia cautelar tuve el honor de asumir). En dicho debate quedó tan estrepitosamente derrotada la posición oficial del anteproyecto ( $y$, previamente, del Borrador) que meses después se anunció que se modificaba la redacción de los artículos correspondientes que ahora en lugar de "sentencia de condena" di- 
rían «sentencia» sin más y harían referencia a la finalidad de asegurar la "tutela» que la sentencia pudiera otorgar. ${ }^{23}$

Pese a tales adelantos, la nueva LEC española sigue mereciendo muchas críticas y no representa la regulación que se necesita para el proceso civil. No ha sabido romper con su planteamiento anticuado y su sistema es contradictorio. En el Art. $5^{\circ}$, al expresar las clases de tutela que es posible pretender, enumera expresamente la tutela cautelar al lado de la de condena, la declarativa, la constitutiva y la ejecutiva. Pero después no reconoce ni la acción cautelar, ni el proceso cautelar ni la sentencia cautelar. Sigue regulando las medidas cautelares a continuación de la ejecución y en el mismo libro, con un criterio abandonado hace tiempo por la mejor doctrina. No conoce las medidas de cautela sustancial o «medidas autosatisfactivas», que tantos y tan fecundos estudios han merecido en este Continente americano, incluidas por la Comisión 'Tarzia en el texto profesoral para la reforma integral del C.P.C. y ni siquiera la extensa exposición de motivos hace la menor alusión a estas nuevas figuras.

El sistema de la nueva LEC es contradictorio consigo mismo, como consecuencia de que, aunque aceptó aquellas críticas, no ha sabido desprenderse del viejo lastre doctrinal. Su tesis central de que las medidas cautelares son para asegurar la sentencia de modo que cuando se inicia la ejecución (provisional o definitiva) solo puede haber ejecución y nunca aseguramiento, el propio legislador —en flagrante contradicción interna- desmiente su planteamiento al disponer en el Art. $700^{\circ}$ para la ejecución en forma específica ("no dineraria», según la ley). "Si el requerimiento para hacer o no hacer o entregar cosas distintas a una suma de dinero no pudiere tener inmediato cumplimiento, el tribunal, a instancia

23 La intervención puede verse publicada en: El proceso civil y su reforma, Madrid, 1998, p. 487 y ss., publicación que incluye las ponencias e intervenciones realizadas en el curso desarrollado bajo la indicada denominación en las dos Universidades de las Islas Canarias (Tenerife y Palma), en la primavera de 1998, auspiciado por la Universidad Alfonso Xel Sabio y por el Gobierno de Canarias, cuyo curso fue dirigido por el Profesor Morón, Catedrático de la Universidad de Tenerife, asistido por D. Domingo Martín Espino, que coordinó las diversas sesiones. En el prólogo el profesor Morón hace una crónica fiel de los sucesivos planteamientos de reforma y renovación de la Ley de Enjuiciamiento Civil durante los siglos XIX y XX.). La intervención se publicó también en otro volumen, de la Universidad Rovira i Virgili, de Tarragona, titulado Presente y futuro del proceso civil, al que se incorporaron las ponencias y comunicaciones del curso celebrado en aquella Universidad, dirigido por el profesor Picó Junoy. 
del ejecutante, podrá acordar las medidas de garantía que resulten adecuadas para asegurar la efectividad de la condena». $Y$ ¿qué son esas "medidas de garantía" para asegurar la efectividad de la condena más que medidas cautelares acordadas en sede de ejecución?. Es más: el segundo párrafo de dicho artículo dispone que «se acordará, en todo caso, cuando el ejecutante lo solicite, el embargo de bienes del ejecutado, en cantidad suficiente para asegurar el pago de las eventuales indemnizaciones sustitutorias y las costas de la ejecución». Pero ese «embargo de bienes para asegurar el pago» no puede ser sino una medida cautelar acordada para asegurar la ejecución. Por si quedase alguna duda, la despeja el párrafo siguiente al disponer que el embargo se alzará si el ejecutado presta caución suficiente. Lo que demuestra paladinamente que se trata de un embargo cautelar aunque acordado al servicio de la ejecución, no de un embargo ejecutivo.

Con todo, desde el punto de vista práctico, el mayor defecto de la nueva LEC es no haber incorporado junto con el sistema cautelar otro de tutela urgente, aunque propiamente no sea cautelar. No ha sabido aplicar esa afirmación tan sabia, que podemos leer en los trabajos de los procesalistas argentinos, como Arazi y Peyrano, que tanto han hecho progresar a la teoría cautelar: «si todo lo cautelar es urgente, no todo lo urgente es cautelar». ${ }^{24}$

b) El futuro proceso civil debe disponer además de una «tutela urgente», no cautelar, que permita una respuesta muy rápida para las situaciones que presentan las sociedades modernas, caracterizadas por su dinamismo. Dejando para la doctrina debatir sobre naturalezas jurídicas, está claro que un proceso civil que responda a las exigencias futuras tiene que disponer de un sistema de tutela urgente, mediante procedimientos tan ágiles que puedan responder a las características y a las exigencias de la vida moderna.

La jurisdicción del «referè» en Francia es una institución sumamente eficaz que además de brindar una protección rápida a un sin fin de situaciones, evita tener que plantear muchos litigios.

Los ilustres colegas argentinos han podido presumir de resoluciones judiciales acordando tutela sumaria de un modo ejemplar (el caso del

24 Cfr. el volumen de trabajos, dirigido por Arazi, Medidas cautelares, Buenos Aires, $2^{\mathrm{a}}$ ed., 1999. Peyrano, El proceso civil, Buenos Aires, 1978; el volumen de diversos autores dedicado a las Medidas cautelares por la Revista de Derecho Procesal argentina. En la doctrina brasileña, Theodoro Junior, Proceso cautelar, $4^{\mathrm{a}} \mathrm{ed} ., 1980$. 
ciclista excluido indebidamente de participar en la Olimpíada de Atlanta, por ejemplo).

c) El Código procesal debe contar con procedimientos para una tutela sumaria y diferenciada. Entiendo que es una tutela eficaz, aunque no sea plena y definitiva. La historia demuestra la utilidad cada vez mayor de los procesos de cognición sumaria junto al proceso de plena cognición. La coexistencia de las dos formas de tutela no es una redundancia absurda. El hecho de que después de lo resuelto en el proceso de cognición sumaria pueda acudirse al juicio plenario es una garantía magnífica que evita todo asomo de indefensión y de atropello. Pero lo que se resuelve en un proceso de cognición sumaria, en un porcentaje altísimo de casos, queda consentido por los interesados y se convierte en definitivo. El ejemplo de los interdictos o acciones posesorias (que la nueva LEC esconde como juicios verbales especiales) o el juicio de desahucio de los ocupantes de un inmueble o el juicio ejecutivo, son ejemplos bien demostrativos de la utilidad de los procesos de cognición sumaria o limitada.

d) En los últimos años del siglo XX algunas legislaciones, angustiadas con el aumento de la litigiosidad, que se traduce en retraso en la respuesta judicial, y con el incremento de casos de oposiciones de mala fe, con "propósito protelatório", como dice el Código de Brasil (Art. 273º, 2), en los casos en que el derecho del actor presenta una fuerte probabilidad de existencia (una verosimilitud cualificada). Han incorporado técnicas de «tutela anticipada», aceptada también, para supuestos concretos, por la reforma procesal italiana.

Nuestra LEC desconoce por completo esta técnica. Inútilmente traté de hacer surgir un debate en torno a esta interesante modalidad de tutela procesal moderna en aquel debate confrontativo sobre el Anteproyecto celebrado en Madrid (que condujo a mejorar el sistema de medidas cautelares). La novedad resultó muy extraña y no interesó en absoluto a los redactores del borrador y del anteproyecto allí presentes. ${ }^{25}$

25 Sobre las diferentes tutelas incorporadas por las legislaciones procesales modernas, cfr. la obra de Dos Santos Bedaque, Tutela cautelar e tutela antecipada: tutelas sumárias e de urgência, Brasil, 1998, en la que trata de la sistematización de todas ellas, que contiene además, atinadas referencias y comparaciones con las correspondientes instituciones de legislaciones comparadas. 
XIV. Los «equivalentes jurisdiccionales» para la solución de conflictos

En todos los países desarrollados los órganos jurisdiccionales -sobre todo los Tribunales superiores o supremos- soportan una carga de trabajo que no pueden atender en un tiempo razonable. Una vía para aligerar la carga de litigiosidad es potenciar las vías de solución de los conflictos de derecho privado mediante las «soluciones alternativas» (la conciliación y especialmente el arbitraje). Además de la utilidad para lograr una litigiosidad soportable por los órganos jurisdiccionales, existen otras razones que aconsejan la utilización de tales vías que Carnelutti llamó gráficamente «equivalentes jurisdiccionales», ya que pueden tener un rendimiento superior al proceso jurisdiccional para el fin de pacificación social y resolución de los conflictos.

La conciliación previa al proceso, regulada en la anterior LEC española como trámite de observancia obligatoria para interponer la demanda, había fracasado. No obstante, en algunos países se reclama hoy su reintroducción. La nueva LEC vigente ha reforzado la conciliación intraprocesal, regulada para el juicio ordinario como primera finalidad de la audiencia previa al juicio (Art. $414^{\circ}$ ). La utilización de la oralidad en el procedimiento, junto a la grabación en vídeo o dvd de las sesiones, con la presencia del juez, ha favorecido que se alcancen más conciliaciones y transacciones que las que se lograban bajo la ley anterior.

$\mathrm{El}$ arbitraje ha tenido un importante desarrollo en los últimos años. La Ley de Arbitrajes de derecho privado de 1953 hubo de ser sustituida por la vigente Ley de Arbitraje No 36/1988, que ha reforzado la utilidad de la institución. Ha desaparecido la antigua distinción entre la «cláusula» compromisoria y el "compromiso", ambas reemplazadas por el "pacto arbitral", apenas sometido a exigencias formales para su validez. $Y$ junto al arbitraje tradicional, pactado para cada caso concreto, se admite el «arbitraje institucional», como una especie de jurisdicción paralela preestablecida no por el Estado pero sí por organizaciones e instituciones oficiales (Colegios de abogados, Cámaras de comercio, etc.), lo que puede plantear rivalidades con la «praeformata tutela» dispuesta por el Estado mediante sus órganos jurisdiccionales. La nueva LEC hoy vigente, ha dado un paso. Ha reforzado la utilidad del arbitraje al admitir que los árbitros puedan acordar medidas cautelares para garantizar la eficacia del laudo arbitral que se dicte.

Para los conflictos laborales existen órganos y procedimientos de «mediación, conciliación y arbitraje». 


\section{$\mathrm{XV}$. Las "litis colectivas" y sus exigencias procesales}

1. La regulación que para esta materia utiliza la nueva LEC española represente el peor de los métodos posibles. $\mathrm{Ni}$ en el borrador ni en el anteproyecto de la LEC se contemplaba tal normativa, ya que la LEC se limitaba a establecer los procesos civiles clásicos, para conflictos individuales o intersubjetivos. Fue en la tramitación parlamentaria del proyecto cuando los grupos políticos decidieron incluir todo un sin fin de enmiendas que frecuentemente empeoraron o confundieron el texto prelegislativo.

Ante la evidencia de que las acciones de grupo son cada vez más frecuentes, nuestros legisladores acordaron incluir en la nueva LEC una regulación de las acciones y conflictos colectivos. Para ello se les ocurrió ir seleccionando las materias o instituciones que creían afectadas por las nuevas acciones a fin de incluir las correspondientes especificaciones. Así, en el Art. $6^{\circ}$, al regular la capacidad para ser parte de las personas físicas o jurídicas y de las masas de bienes o grupos de personas sin personalidad, incluido el «nasciturus», añadieron también una previsión para los consumidores y/o usuarios (núm. 7 del Art. $6^{\circ}, 1$ ). Otro tanto se ha hecho en el Art. $7^{\circ}$, núm. 7 , en cuanto a la capacidad procesal de las asociaciones constituidas o a constituir por los afectados. Lo mismo en cuanto a la legitimación: después de regular en el Art. $10^{\circ}$, la legitimación por la titularidad afirmada o por sustitución, el Art. $11^{\circ}$ regula la legitimación para la defensa de derechos e intereses de los consumidores. De igual modo se ha procedido al regular la intervención de terceros interesados en el proceso (arts. $13^{\circ}$ y $15^{\circ}$ ) y, singularmente, al regular el contenido de la sentencia en las acciones colectivas (Art. 221 ${ }^{\circ}$ ) y el efecto de cosa juzgada y sus límites (Art. 222\%, 3).

De ese modo, nuestro legislador optó por fraccionar o apedazar la regulación de los ingentes problemas que plantean estas modernas acciones colectivas, para tutelar intereses individuales homogéneos, o intereses colectivos o difusos, injertando en las correspondientes instituciones procesales una "contrarregulación" de la establecida para los litigios intersubjetivos. Nuestro legislador habría debido dejar esta materia fuera de la nueva LEC. Al igual que se ha hecho con la regulación de los procesos de quiebra, que pasan a una ley especial de próxima promulgación, la nueva LEC ha debido seguir la misma metodología con las acciones de grupo, dejando su normativa para una ley o código específico, lo que 
permitiría una regulación integral de la materia como se ha hecho en las legislaciones más adelantadas, como el Código de los consumidores de Brasil.

Pero es más: puestos a incorporar la regulación a la nueva LEC por la idea obsesiva del legislador de convertirla en ley procesal general o común, al menos debería haberse creado un proceso civil especial para estas acciones, con una regulación reunida en un mismo pasaje legal. Los procesos para la defensa de intereses colectivos son tan importantes y complejos que nadie que tenga una mínima información sobre esta materia puede dudar sobre la conveniencia de disponer de una regulación «ad hoo, bien en un cuerpo legal específico o, como mínimo, en un pasaje de la ley procesal. La regulación fragmentada o apedazada por la que optó nuestro legislador resulta a veces esquizofrénica al incluir para la misma institución ( vg. la legitimación o la cosa juzgada) dos regulaciones contradictorias entre sí, una para los litigios individuales y otra para los litigios colectivos. Además, creará problemas prácticos que impedirán que los procesos por las acciones de grupo funcionen eficazmente. Basta pensar que el molde del «juicio ordinario" (con sus plazos de prueba establecidos para litigios individuales) no es apto para este tipo de procesos.

Creo que sin tener que invocar grandes dotes para la profecía, puedo prever que la regulación de la nueva LEC solo por las razones indicadas, tendrá que ser pronto derogada, como una normativa claramente insuficiente, sin contar con la falta de respuesta de los nuevos preceptos a algunos de los ingentes problemas que en este tipo de acciones se plantean. Este importante aspecto de la nueva LEC no ha sido debatida entre personas conocedoras de los problemas que se plantean, problemas que desde luego no conocen los diputados ni los senadores que en la democracia española son elegidos por los respectivos partidos políticos para representar al pueblo.

2. Para mí, el mejor modelo legislativo a seguir es el del Brasil, donde eminentes colegas orientaron la obra legislativa mediante la promulgación de un "Código de Consumidores", que contiene una regulación completa de la materia. ${ }^{26}$

Es el mismo método que se va a seguir por el Instituto, al haber acordado en el Congreso de Roma la elaboración de un "Anteproyecto de

26 Codigo Brasileiro de Defesa do Consumidor, (comentada por los autores del anteproyecto, $6^{a}$ ed., 1999). 
Código Modelo de procesos colectivos para Iberoamérica», que el Presidente Berizonce ya ha sido circulado a todos los miembros del Instituto.

Al llevar ese trabajo la firma de especialistas tan renombrados y competentes como la profesora Pellegrini Grinover y los profesores Watanabe y Gidi, yo solo puedo hacer mías los planteamientos y tesis de dicho Anteproyecto, al cual me remito como referencia o arquetipo de regulación de esta importante materia, que sin duda va a tener un lugar muy destacado en el proceso civil del futuro. ${ }^{27}$

XVI. Flexibilización y nueva eficacia de la cosa juzgada

"Hic sunt leones'», como suele escribir a Fairén cuando nos encontramos frente a una gran dificultad.

1. Yo no puedo dejar de evocar a mi maestro en la Universidad, el profesor Guasp (el más brillante de todos los eminentes profesores de todas las disciplinas que habían coincidido en aquella Facultad de Derecho de la Universidad Complutense) cuando, como retórico excepcional y profesor peripatético, paseando entre las filas de alumnos por los pasillos del aula, llegada la lección de la cosa juzgada repetía con palabra elegante y precisa y voz sonora los famosos dísticos de Scaccia: ${ }^{28}$

"Res iudicata facit de albo nigrum;

«aequalat quadrata et rotundis;

«naturalia sanguinis vincula

«et falsum in verm mutat

Años después, consultando el «Tractatus de re iudicata» he comprobado que Scaccia, seguramente consciente de que a pesar de la sentencia, lo blanco no se hacía negro ni lo cuadrado se igualaba con lo redondo, añadía el argumento definitivo: y «no tenemos que preocuparnos» («non est curandum») de si lo declarado es verdadero o falso porque lo que dijo la

27 Recientes observaciones sobre los problemas planteados por la tutela de estos intereses han sido formuladas por Punzi, "La tutela giudiziale degli interessi difusi e degli interessi collettivi», en: Rivista di Diritto Processuale, 2002, № 3, p. 6476 y ss.

28 Guasp, Derecho Procesal Civil, 1º ed., Madrid-España, 1956, pp. 595-598. 
sentencia «lo recibimos y aceptamos como verdad» ("pro iam veritate accipiturn).

En una época llena de dogmas y propensa a los mitos, el dogma de la cosa juzgada, quedaba rodeada de "santidad" y se tomaba técnicamente como "presunción de verdad", solo destructible en los contados casos abiertos a la revisión. La "santidad de la cosa juzgada» venía a ser la religión de la justicia humana.

Pero el mismo Guasp, al analizar el fundamento de la cosa juzgada, explicaba y dejó escrito después que «el valor de justicia permanece indiferente a la cosa juzgada; incluso en muchas veces le es hostil» y entra en conflicto con ella, porque al valor de justicia repugna que una decisión judicial permanezca inmutable aunque se patentice su discrepancia con el orden jurídico substancial. En cambio, «el valor de la seguridad jurídica postula la existencia de cosa juzgada, por cuanto sin ella las situaciones jurídicas materiales estarían en trance de perpetua revisión». Y concluía que «a cosa juzgada es una de tantas concesiones que la justicia hace a la seguridad jurídica para la mejor obtención del bien común». ${ }^{29}$.

Me parece que estas palabras con las que Guasp resume su tesis tienen hoy una validez superior a la que les correspondía en la época en la que fueron escritas.

A su significación dogmática y a su «santidad» la cosa juzgada unió un singular prestigio doctrinal, ya que en torno a ella se han formulado múltiples explicaciones teóricas, con un planteamiento material o materialista de los efectos de la cosa juzgada o con un planteamiento solo procesal o procesalista de tales efectos, teorías de cuya dificultad da cuenta un libro muy poco conocido de nuestro maestro Gómez Orbaneja titulado precisamente "Las teorías sobre la cosa juzgada». Una materia tan difícil y cultivada por los más eminentes autores ha sido siempre un "tema vitando" para los jóvenes investigadores que atraídos por las explicaciones del profesor pretendían realizar nuevas aportaciones, que solo podían estar reservadas a autores como Satta, con su construcción monista, y, sobre todo, a un autor que siempre supo poner luz donde había oscuridad. Me refiero a Liebman y a su monografía "Autoridad y eficacia de la sentencia", una de las obras verdaderamente importantes en la literatura procesal del pasado siglo, que por algo ha sido traducida a diversos idiomas. ${ }^{30}$

29 Id., p. 597

30 Liebman, Efficacia ed autorità della sentenza, Milano, 1962. Se tradujo al español por Sentis Melendo, Eficacia y autoridad de la sentencia, Buenos Aires, 1946 y al portu- 
2. No es posible-mucho menos en Montevideo-dejar de evocar aquella bella frase de Couture, una de las muchas que abundan en sus «Fundamentos", cuando utiliza la cosa juzgada como la piedra de toque de la jurisdicción recordando que "una Constitución puede derogarse y sustituirse por otra Constitución; una Ley puede dejarse sin efecto y ser cambiada por otra ley; un acto administrativo puede ser revocado y sustituido por otro acto administrativo. Pero una sentencia judicial pasada en autoridad de cosa juzgada, no puede revocarse, sustituirse ni cambiarsem. ${ }^{31}$

Pero también ahora hay que colocar otro texto de Couture cuando poco después advierte que «la cosa juzgada ganada con fraude no vale». $Y$ en el debate exaltado entre las dos exigencias contrapuestas, la justicia y la seguridad, el Maestro uruguayo se remite al último discurso de Sócrates a sus discípulos. ${ }^{32}$

Creo que este segundo texto de Couture, como el de Guasp, nos orientan hacia las nuevas tendencias ya formuladas sobre el papel de la cosa juzgada en el futuro proceso civil. Tendencias que pueden resumirse en lo que Dinamarco ha llamado recientemente «flexibilización de la cosa juzgada» $y$ en sus «nuevos efectos» 0 «nuevos límites». ${ }^{33} \mathrm{Y}$ es que, en definitiva, cuando se plantea la "flexibilización" de la cosa juzgada o sus nuevos "límites» lo que se está propugnando es un nuevo marco para las concesiones que la justicia debe hacer a la seguridad, ahora con un predominio de las exigencias de justicia para una paz social más justa, como ya puede advertirse en la nueva edición de «La revisión» del Prof. Hitters. ${ }^{34}$

3. Según la posición tradicional que ha llegado vigente hasta nuestros días, la cosa juzgada despliega sus efectos «inter partes et non secundum eventum litis». De acuerdo con esa fórmula se definen los límites subjeti-

gués en una traducción brasileña realizada por Buzaid y Airres, Eficácia e autoridade da sentença, Río de Janeiro, 1981.

31 Couture, Fundamentos del derecho procesal civil, $3^{\text {a }}$ ed., Buenos Aires, 1958.

32 Couture, Fundamentos [...] op.cit., y «Revocación de los actos procesales fraudulentos", en: Estudios de Derecho Procesal Civil, III, Buenos Aires, 1978.

33 Dinamarco, en sus obras $A$ instrumentalidade do proceso y Teoria General do Proceso. Y más recientemente en el trabajo publicado con este título "Relativizar a coisa julgada» material en: Cuadernos procesales (órgano del Colegio de Profesores de Derecho Procesal de la Facultad de Derecho de la UNAM) año V, N 14, dic., 2001, pp. 3-22.

34 Hitters, en la nueva edición de su monografía Revisión de la cosa juzgada (con la colaboración de M. O. Hernández y prólogo de Morello), La Plata, 200l, seguido en España por Vallespin en: La revisión civil, Barcelona-España, 2002. 
vos de la institución, que afectan a los que han litigado y a quienes de ellos traigan causa, sin importar cual haya sido el resultado del litigio (una eventualidad intrascendente para la cosa juzgada).

a) No obstante, dentro de un proceso intersubjetivo, de personas concretas y determinadas, varias brechas se han tenido que abrir en esa concepción:

En primer lugar, ha tenido que admitirse la cosa juzgada con efectos subjetivos ilimitados, "erga omnes", para las acciones de estado y condición de las personas (no podría ser que la filiación o la incapacitación establecida en la sentencia tuviese valor solo para los litigantes y no frente a los demás). La presencia del Ministerio Público en estos procesos así como su inscripción en el Registro civil, e incluso en otros registros oficiales de publicidad, anticipan el valor no limitado de las sentencias en estos casos. Ha tenido que admitirse también la legitimación de cualquier comunero para accionar en interés de toda la comunidad, con la consecuencia de que el efecto de la cosa juzgada que pueda derivar de la sentencia favorezca a quienes no litigaron, desbordándose así los límites subjetivos de la institución.

En el proceso civil clásico, la doctrina cuenta con muy valiosos estudios sobre la "cosa juzgada respecto de los terceros", siendo obligado recordar una monografía de Allorio como aportación fundamental en la materia. ${ }^{35}$

b) Pero los procesos colectivos han hecho surgir nuevos problemas, ciertamente difíciles, que obligan a revisar importantes aspectos de la eficacia tradicionalmente atribuida a la cosa juzgada, sobre todo en cuanto a los límites.

Se reconoce para las sentencias dictadas en procesos en los que se ejercitan acciones colectivas, además del efecto tradicional «inter partes», las siguientes categorías de cosa juzgada:

35 Allorio, Cosa giudicata rispetto ai terzi, Milano, 1935, en la que sostuvo la tesis de que de las dos explicaciones tradicionales de la cosa juzgada la teoría procesal se concilia mejor con la limitación de la autoridad de lo juzgado solo a las partes, mientras que la teoría sustancial es más útil si se plantea el principio de la eficacia de la cosa juzgada frente a todos (sin perjuicio de una eficacia de cosa juzgada absoluta respecto de las partes). Posteriormente ha insistido en esta conclusión: Cfr. Allorio, Sulla dottrina della giurisdizione e del giudicato (e altri studi), Milano, 1957. 
- Cuando la acción verse sobre intereses o derechos individuales de muchas personas, pero que son intereses homogéneos, la sentencia que acoja la demanda produce efectos «erga omnes», a fin de beneficiar a todos los afectados y a sus causahabientes.

- Cuando la acción se refiera a intereses o derechos colectivos, la sentencia que haya estimado la demanda, produce efectos «ultra partes», aunque limitados a los integrantes del grupo, clase o categoría de afectados, a fin de que todos resulten favorecidos por el resultado del proceso colectivo.

- Cuando la acción ejercitada se refiera a intereses o derechos difusos, la sentencia que acoja la demanda produce efectos "erga omnes" para todos los afectados, de imposible determinación individual.

La acción colectiva no debe perjudicar las acciones que a título individual se puedan ejercitar. Los efectos de la cosa juzgada quedan limitados al grupo o colectivo.

Hasta aquí la nueva eficacia de las sentencias recaídas en los procesos colectivos no suponen una gran quiebra del planteamiento tradicional. El problema verdaderamente más difícil es el que se presenta cuando la sentencia no acoja la demanda sino que la desestime. Uno de los peligros a prevenir en este tipo de acciones son las demandas simuladas e incluso fraudulentas ( $v g$. un grupo demanda contra una publicidad engañosa, pero lo hace de tal modo que en realidad va procurando la desestimación de la acción para crear una cosa juzgada adversa a los demandantes y favorable al demandado para invocarla después si se interponen otras acciones). La desestimación de la demanda puede producirse por diversas razones y una de ellas puede ser la insuficiencia de las pruebas practicadas en el proceso colectivo. Como ha quedado indicado tal insuficiencia de pruebas puede haber sido buscada incluso de propósito por los pseudodemandantes.

En estos supuestos cabría adaptar las vías de la revisión de las sentencias firmes, creando incluso una vía específica. Pero como no todos los casos serán de fraude, sino que habrá también demandas que fracasen por impericia profesional o por no haber podido disponer de las pruebas adecuadas, las legislaciones más avanzadas (como el Código de los Consumidores de Brasil) optan por permitir en estos casos que cualquier legitimado como integrante del grupo o colectivo pueda promover otra acción con el mismo fundamento pero ofreciendo nuevas pruebas que no fue posible utilizar en el proceso anterior. La exclusión en estos casos del efecto de la 
cosa juzgada ha permitido afirmar que las sentencias en tales casos producen cosa juzgada "secundum eventum litis» (la producen las que estimen la demanda y no las que la rechacen si la causa del rechazo es la inexistencia o insuficiencia de pruebas) o de "res iudicata secundum probationem", lo que es ciertamente chocante y hace chirriar la institución.

Seguramente es este uno de los signos de los nuevos tiempos, definido por Barbosa Moreira como «tránsito de lo individual a lo colectivo». ${ }^{36}$

c) Para la doctrina española, que la cosa juzgada pueda operar "secundum eventum litis» o incluso "secundum probationem», resulta verdaderamente escandaloso. Para rebajar el escándalo quiero señalar que en el nuevo proceso administrativo (o "contencioso-administrativo" según nuestra pleonástica denominación) ya han aparecido nuevas figuras de cosa juzga$\mathrm{da}$, que afectan a terceros de un modo hasta ahora desconocido y que pueden servir como anticipo de los próximos tiempos:

El Art. $72^{\circ}$ (núm. 1) de la nueva Ley No29/1998, establece que:

"la sentencia que declare la inadmisibilidad (del proceso, en España llamado "recurso») o que desestime la demanda «solo producirá efectos entre las partes" mientras que "la sentencia que anule una disposición o un acto administrativo "producirá efectos para todas las personas afectadas", estableciendo también que "las sentencias que anulen una disposición general tendrán efectos generales» desde el día en que la sentencia se haga pública ("efectos generales» significa lo mismo que efectos "erga omnes"), excluyéndose solo de tales efectos las sentencias o actos administrativos ya firmes que hayan aplicado el precepto o disposición anulado». ${ }^{37}$

36 Barbosa Moreira, Comentàrios ao Código de Processo Civil, V, 8a ed. Rio, 1999.

37 El Art. $72^{\circ}$, No 1 y 2 , de la nueva Ley de la Jurisdicción contencioso-administrativa (Ley No 29/98) dice así :

"1 La sentencia que declare la inadmisibilidad o desestimación del recurso contencioso administrativo solo producirá efectos entre las partes".

“2. La anulación de una disposición o acto producirá efectos para todas las personas afectadas. Las sentencias firmes que anulen una disposición general tendrán efectos generales desde el día en que sea publicado su fallo y (los) preceptos anulados en el mismo periódico oficial en que lo hubiese sido la disposición anulada».

El Art. $73^{\circ}$ regula la eficacia temporal de la sentencia de anulación, que normalmente es solo para el futuro y no "ex tunc».

El Art. $110^{\circ}$ establece: 
Mas importancia tiene todavía el Art. $110^{\circ}$ de dicha Ley Jurisdiccional, relativo a las demandas en materia de tributos y de personal al servicio de la Administración pública, el cual dispone que "los efectos de una sentencia firme que hubiera reconocido una situación jurídica individualizada a favor de una o varias personas "podrán extenderse a otras en ejecución de la sentencia» siempre que los interesados se encuentren en idéntica situación jurídica que los favorecidos por la sentencia y lo soliciten, regulando un procedimiento incidental en sede de ejecución para hacer efectiva el efecto extensivo de la sentencia".

Las brechas abiertas por estos preceptos en el sólido muro de la cosa juzgada tradicional son desde luego "signos de los tiempos", que obligan a renovar muchas instituciones que creíamos intocables e irremovibles.

Para nuestra tranquilidad hemos de recordar que el derecho existe por y para la sociedad. Como dijo en una expresión afortunada el Prof. Guasp, en su obra de filosofía: «el derecho es una conspiración para la convivenciam. ${ }^{38}$ El derecho trata de lograr, en cada etapa de la historia, una convivencia basada en una vida humana justa y pacífica. Y para ello debe adaptarse cuanto sea necesario a las circunstancias y exigencias de cada época.

Adda. - Diversas urgencias y limitaciones me han impedido plantear la necesidad de empezar a abrir la vía (procesal y sustancial) de una tutela preventiva, antes de que se produzcan las lesiones a las situaciones

"1. En materia tributaria y de personal al servicio de la Administración pública, los efectos de una sentencia firme que hubiera reconocido una situación individualizada a favor de una o varias personas podrán extenderse a otras, en ejecución de la sentencia, cuando concurran las siguientes circunstancias:

«a) Que los interesados se encuentren en idéntica situación jurídica que los favorecidos por el fallo.

«b) Que el Juez o Tribunal sentenciador fuera también competente, por razón del territorio, para conocer de sus pretensiones de reconocimiento de dicha situación individualizada.

«c) Que soliciten la extensión de los efectos de la sentencia en el plazo de un año desde la última notificación de ésta a quienes fueron parte en el proceso. Si se hubiere interpuesto recurso en interés de la Ley o de revisión, este plazo se contará desde la última notificación de la resolución que ponga fin a estem.

A su vez el Art. $11^{\circ}$, para los casos en los que se hubiere acordado suspender la tramitación de uno o más recursos, según lo previsto en el Art. 37o, 2, de la ley, los recurrentes (mejor, demandantes) afectados por la suspensión podrán interesar del Juez o Tribunal que se extienda a su favor los efectos de la sentencia o sentencias firmes dictadas en los recursos (mejor, procesos) ya resueltos.

38 Guasp, Derecho, 1971, $\$ 1$. 
protegibles, frente a la actual tutela reparadora o sancionadora, sobre cuyo aspecto pude anticipar algunos planteamientos en el Congreso celebrado este mismo año en Roma, el pasado mes de mayo. Quede hecha la remisión, con el sometimiento de las opiniones que anteceden al mejor criterio de los Ilustres Colegas participantes en las XVIII Jornadas procesales iberoamericanas y ahora también a la de los amables lectores. ${ }^{39}$

$39 \mathrm{El}$ presente trabajo reproduce, con ligeras correcciones, la ponencia presentada en las "XVIII Jornadas del Instituto Iberoamericano", celebradas en Montevideo (junto con las "XI Jornadas Nacionales") los días 16-18 de octubre de 2002, expuesto en el panel de la segunda sesión del día 18 . 